\author{
UNIVERSIDADE DE SÃO PAULO - USP \\ FACULDADE DE ECONOMIA, ADMINISTRAÇÃO E CONTABILIDADE \\ DEPARTAMENTO DE ECONOMIA \\ PROGRAMA DE PÓS-GRADUAÇÃO EM ECONOMIA
}

\title{
Crédito Direcionado e Desenvolvimento Econômico: Uma avaliação da política de crédito brasileira
}

Mailliw Serafim de Siqueira Silva Orientador: Gabriel de Abreu Madeira

São Paulo

2018 
Prof. Dr. Vahan Agopyan

Reitor da Universidade de São Paulo

Prof. Dr. Adalberto Américo Fischmann

Diretor da Faculdade de Economia, Administração e Contabilidade

Prof. Dr. Eduardo Amaral Haddad

Chefe do Departamento de Economia

Prof. Dr. Ariaster Baumgratz Chimeli

Coordenador do Programa de Pós-Graduação em Economia 


\section{Mailliw Serafim de Siqueira Silva}

\section{Crédito Direcionado e Desenvolvimento Econômico: Uma avaliação da política de crédito brasileira}

Dissertação apresentada ao Departamento de Economia da Faculdade de Economia, Administração e Contabilidade da Universidade de São Paulo como requisito parcial para a obtenção do título de Mestre em Economia.

Orientador: Gabriel de Abreu Madeira

Versão Corrigida

São Paulo 


\section{FICHA CATALOGRÁFICA}

Elaborada por Rafael Mielli Rodrigues - CRB-8/7286

Seção de Processamento Técnico do SBD/FEA/USP

Silva, Mailliw Serafim de Siqueira

Crédito direcionado e desenvolvimento econômico: uma avaliação da política de crédito brasileira / Mailliw Serafim de Siqueira Silva. -- São Paulo, 2018.

$65 \mathrm{p}$.

Dissertação (Mestrado) - Universidade de São Paulo, 2018.

Orientador: Gabriel de Abreu Madeira.

1. Sistema financeiro 2. Banco de crédito 3. Desenvolvimento econômico I. Universidade de São Paulo. Faculdade de Economia, Administração e Contabilidade. II. Título.

$\mathrm{CDD}-332$ 
Para Dida 



\section{Agradecimentos}

Primeiro, gostaria de agradecer meus pais, William e Dalveli, que apesar de todas as dificuldades sempre lutaram para que eu tivesse a melhor educação possível.

Em seguida, gostaria de agradecer ao meu orientador, Gabriel Madeira, por ter se mostrado bastante solícito durante todo o desenvolvimento deste trabalho. Foi um grande prazer e aprendizado ter tido um orientador sempre interessado em discutir novas ideias.

Agradeço ao Tiago Cavalcanti, por ter, gentilmente, acompanhado e ajudado o desenvolimento de parte deste trabalho. Como também agradeço aos professores Mauro Rodrigues e Marcos Nakane pelos comentários e sugestões em versões preliminares deste trabalho.

Agradeço ao Banco Central do Brasil, em especial ao Sergio Mikio, que disponibilizaram as bases de dados que viabilizaram a execução deste trabalho e também por terem colaborado com comentários e sugestões.

Agradeço a FAPESP, por ter dado o apoio financeiro que viabilizou a realização deste projeto.

Não poderia deixar de agradecer ao Professor Juarez Rizzieri, que em um momento onde minha vida acadêmica se colocou em risco, me ajudou a prosseguir nessa jornada.

É impossível deixar de agradecer ao Hector Luz, companheiro de longa data que me acompanha desde o início da minha aventura acadêmica, estando sempre disposto a ajudar e a trocar ideias.

Por fim, é especial minha gratidão a Natália, por ser minha companheira em todos os momentos e por tomar meus sonhos como os dela. 



\section{Resumo}

No Brasil, cerca de $40 \%$ do crédito às firmas tem como orígem recursos oriundos de políticas de direcionamento. Estes empréstimos são fortemente subsidiados, com taxas de juros substancialmente inferiores às dos demais. No entanto, apenas cerca de $16 \%$ das firmas formais são beneficiadas por estes empréstimos, sendo que estas firmas recebem cerca de $80 \%$ do total do crédito bancário a empresas. É razoável supor que os efeitos dessas políticas sobre a economia sejam substanciais. Para avaliá-los, construímos um modelo de equilíbrio geral com agentes heterogêneos e restrições de crédito, que incorpora regras de direcionamento que buscam replicar as políticas praticadas no Brasil. Com o apoio de técnicas recentes de solução númérica de modelos dinâmicos, ajustamos o modelo a dados de crédito e emprego por firma e examinamos o efeito da remoção das políticas de direcionamento. O modelo prevê que a extinção dos programas de crédito direcionado geraria diversos efeitos positivos, como aumento do produto e da produtividade, redução de desigualdade e inclusão financeira. Em seguida, examinamos variações nas políticas de direcionamento, avaliando os impactos de dar maior foco a empreendedores mais pobres ou mais produtivos. Embora estas mudanças possam gerar melhorias, nossos resultado apontam ganhos menores que a mera remoção dos programas de direcionamento.

Palavras-chaves: SISTEMA FINANCEIRO. BANCO DE CRÉDITO. DESENVOLVIMENTO ECONÔMICO. 



\section{Abstract}

The present work aims to evaluate the effects of earmarked credit programs in the Brazilian economy. For this purpose, will be developed a general equilibrium model with heterogeneous agents, capable of reproducing the structure of the Brazilian credit market. This model will be calibrated using the data from the RAIS (Annual Information Report) and the SCR (Credit Information System), in order to carry out counterfactual exercises by changing the parameters of the credit policy. As a result, it is found that the end of earmarked credit programs generates a product increase, reduces inequality and the average size of firms, as well as increases productivity, the financial inclusion of firms and the welfare. In addition, the gains generated by the closure of such programs have been shown to be greater than alternative policies, such as targeting the earmarked credit the most productive individuals or the poorest.

Key-words: FINANCIAL SYSTEM. CREDIT BANK. ECONOMIC DEVELOPMENT. 



\section{Sumário}

INTRODUÇÃo $\ldots \ldots \ldots \ldots \ldots \ldots \ldots \ldots$

O CRÉdITO DIRECIONADO NO BRASIL . . . . . . . . . 15

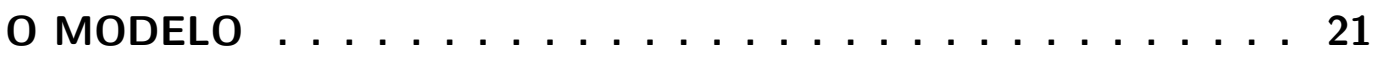

A estrutura do Modelo

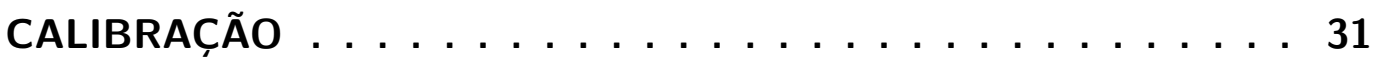

EXERCÍCIOS CONTRAFACTUAIS . . . . . . . . . 39

$5.1 \quad$ Extinção do programa de crédito direcionado . . . . . . . 39

$5.1 .1 \quad$ Robustez . . . . . . . . . . . . . . . . . . 41

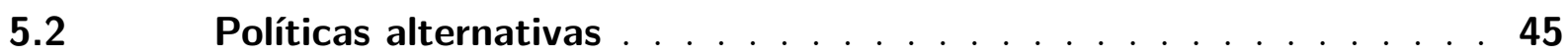

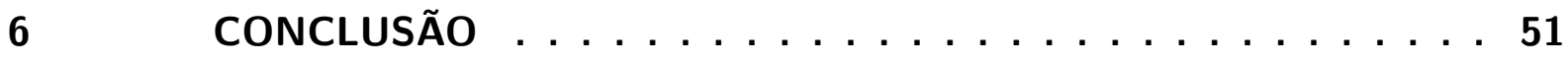

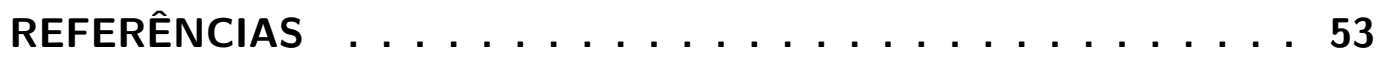

APÊNDICES

APÊNDICE A - DERIVAÇÕES TEÔRICAS . . . . . . . 57

A.1 Derivação do Processo de Difusão da Produtividade . . . . . . . 57

A.2 Derivação da Hamilton-Jacobi-Bellman . . . . . . . . . . . 57

A.3 Derivação da Equação de Euler . . . . . . . . . . . . 58

APÊNDICE B - MÉTODO NUMÉRICO . . . . . . . . . . 61

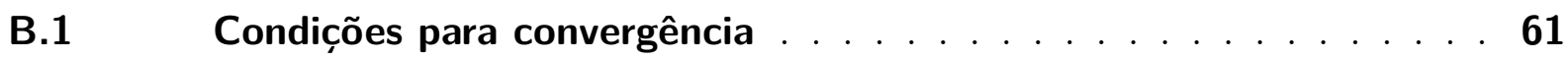

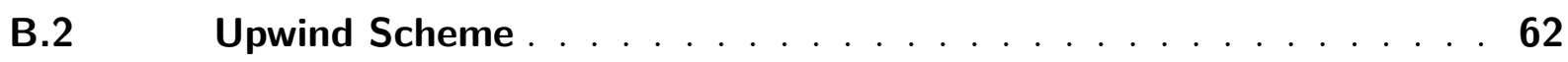

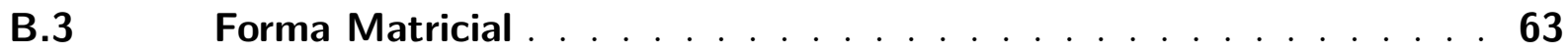

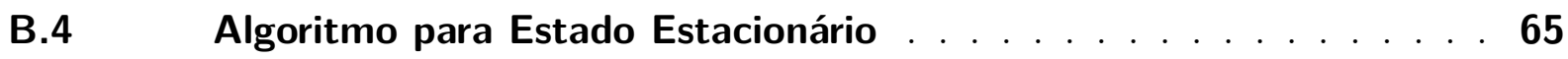





\section{Introdução}

Uma larga porção da literatura de desenvolvimento econômico dedica-se ao estudo do crédito e demais instrumentos de intermediação financeira. A distribuição de recursos disponíveis para investimento entre múltiplas alternativas de produção se dá fundamentalmente através dos mecanismos de intermediação financeira, e o bom funcionamento destes mecanismos é crucial para uma alocação eficiente de recursos produtivos. No Brasil, não se pode avaliar a eficácia da intemediação financeira sem que se considere políticas de direcionamento de crédito. No ano de 2015, cerca de $40 \%$ do crédito utilizado pelas firmas teve como orígem recursos oriundos de políticas de direcionamento. As taxas de juros destes empréstimos são consideravelmente menores do que as taxas cobradas no mercado de crédito livre, devido a fortes subsídios implícitos ou explícitos. A distribuição destes recursos está longe de ser homogênea. Apenas cerca de 16.3\% das firmas formais tem contratos de crédito direcionado, sendo que estas firmas recebem cera de $80 \%$ do total de crédito bancário da economia (entre crédito livre e direcionado). Dada a magnitude dos programas de direcionamento de crédito, é razoável supor que eles afetem substancialmente um amplo conjunto de variáveis econômicas, e que seus efeitos se estendam muito além das firmas diretamente beneficiadas por eles.

Este artigo avalia os impactos de longo prazo das políticas de direcionamento sobre a economia brasileira. Com este objetivo, construímos e calibramos um modelo dinâmico de equilíbrio geral com escolha ocupacional ao qual incorporamos regras de direcionamento que buscam replicar as políticas praticadas no Brasil. Considerando-se que as políticas de direcionamento não se distribuem homogeneamente entre firmas e que o crédito é particularmente relevante para alguns tipos de indivíduos, como empreendedores com bons projetos mas pouco capitalizados, o modelo incorpora heterogeneidade entre agentes econômicos em três dimensões: riqueza, talento e disponibilidade de crédito direcionado ${ }^{1}$. O modelo é rico suficiente para gerar predições sobre impactos do direcionamento sobre uma ampla gama de variáveis econômicas, incluindo produtividade, desigualdade, empreendedorismo e uso de instrumentos financeiros. Esta riqueza impõe importantes desafios computacionais, mas o arcabouço inovador para modelos em tempo contínuo proposto por Achdou et al. (2017), torna o problema tratável. De fato, a formulação adotada é suficientemente eficaz para permitir que os parâmetros do modelo sejam escolhidos de maneira a gerar um bom ajuste

1 Conforme mostra Banerjee (2003), há evidência empírica de que os impactos do funcionamento imperfeito do mercado de crédito recai de forma diferente entre os indivíduos. Tipicamente os mais ricos são capazes de tomar maiores volumes emprestados e pagar taxas de juros menores. Banerjee e Duflo (2010) constróem alguns modelos simples para explicar a heterogeneidade em taxas de juros. A interação entre as imperfeições no mercado de crédito e outras variáveis, como a renda e riqueza, podem afetar os impactos das fricções financeiras na economia e o resultado de intervenções. 
a um rico conjunto de dados sobre crédito e firmas à disposição do Banco Central do Brasil.

Na ausência de externalidades ou imperfeições de mercados (como em Lucas (1978)), intervenções como o direcionamento de crédito fatalmente gerariam ineficiências, que as tornariam injustificáveis. No entanto, mercados de crédito são fortemente afetados por friç̧ões, sejam elas derivadas de assimetrias informacionais ou de comprometimento limitado (ver por exemplo Paulson, Townsend e Karaivanov (2006)). Havendo fricções no mercado de crédito, não é a princípio claro se políticas como o direcionamento trazem maiores benefícios ou prejuízos ${ }^{2}$. Em nosso modelo, incorporamos um tipo de fricção facilmente tratável que é comum na literatura a ele associada: limitações na capacidade de endividamento resultantes de comprometimento limitado (similarmente às apresentadas em Banerjee e Duflo (2010)). Nestas condições, apesar de seus efeitos potencialmente distorsivos, subsídios podem contribuir para aliviar restrições de crédito.

Os efeitos do direcionamento sobre a economia são estimados a partir de exercícios contrafactuais em que removemos as políticas de direcionamento em versões calibradas do modelo. Em todos os exercícios efetuados, o modelo prevê que a retirada de direcionamento geraria ganhos de produtivodade, melhorias na distribuição de renda, aumentos de salários e inclusão financeira. Em seguida, avaliamos efeitos de variações nas regras de direcionamento, apreciando os impactos de aumentar a participação de indivíduos com menor riqueza ou maior produtividade entre os que recebem crédito direcionado. Embora alguns destes exercícios gerem melhorias nos resultados do direcionamento, eles ainda apresentam resultados menos positivos do que a mera remoção dos programas.

Nosso trabalho contribui para a vasta literatura recente que avalia impactos de imperfeições no mercado de crédito sobre a produtividade agregada. A literatura de crescimento econômico (por exemplo Banerjee e Duflo (2005), Alfaro, Charlton e Kanczuk (2008), Restuccia e Rogerson (2008) e Hsieh e Klenow (2009)) reconhece que a alocação sub-ótima de recursos produtivos entre firmas (usualmente chamada de misallocation) é responsável por uma larga parcela das diferenças de produtividade entre países. Conforme demonstram Banerjee e Moll (2010), restrições de crédito podem gerar alocação sub-ótima de recursos produtivos ao impedir a equalização das produtividades marginais do capital entre as firmas (misallocation na margem intensiva), além de levar indivíduos que idealmente deveriam ser empreendedores a trabalhar como assalariados (misallocation na margem extensiva). Alguns estudos empíricos orientados por modelos sugerem que

$\overline{2}$ Stiglitz (1993) destaca que a evidência da efetividade das intervenções governamentais é mista, sendo possível que a política implementada gere ainda mais distorções ao invés de resolver o problema. Além disso, tais programas podem falhar em atingir seus objetivos devido a problemas de agência gerados pelos incentivos inerentes ao setor público, conforme aponta Banerjee (1997). 
melhorias no sistema financeiro têm um potencial significativo de geração de ganhos de produtividade. Estimativas feitas por Jeong e Townsend (2007) sugerem que cerca de $75 \%$ dos ganhos de produtividade ao longo de 20 anos na Tailândia são resultantes de aprofundamento financeiro e realocações ocupacionais associadas. Usando microdados da economia americana, Midrigan e Xu (2014) encontram resultados indicativos de que, embora fricções financeiras gerem um efeito modesto de misallocation na margem intensiva, seus impactos negativos sobre produtividade são substanciais quando se considera seu efeito inibidor de entrada de firmas e adoção de novas tecnologias.

Neste artigo, o interesse não é estudar o impacto de restrições de crédito, mas sua interação com políticas que têm como um de seus objetivos mitigá-las. Assim também procedem Buera, Moll e Shin (2013), que analisam o caso em que crédito subsidiado é dado para os empresários mais produtivos em um contexto em que a produtividade evolui de forma estocástica no tempo. No curto prazo, tais programas têm o efeito desejado, aumentando o produto e a produtividade. Mas no longo prazo, conforme a produtividade dos indivíduos que acessam o crédito direcionado reverte para a média, a decisão de entrada das firmas é distorcida, permitindo que empresários pouco produtivos se mantenham ativos e impedindo indivíduos mais produtivos de entrarem no mercado. Portanto, estes programas geram perda de produto e queda da produtividade no longo prazo. Similarmente, Buera, Kaboski e Shin (2012) estudam o caso no qual o governo implanta programas de microcrédito para favorecer pequenas empresas. Usando um modelo de equilíbrio geral, os autores chegam à conclusão que os programas de micro-crédito elevam a produtividade, porém tal efeito é contrabalanceado por uma menor acumulação de capital gerada pela transferência de renda de indivíduos mais ricos para os mais pobres. O efeito líquido é um pequeno aumento do produto per capita. Contudo, a maioria da população é beneficiada pelo programa analisado, na medida em que ele eleva os salários de equilíbrio.

Alguns trabalhos já trataram das políticas de direcionamento de crédito no Brasil. Usando microdados em painel, Bonomo, Brito e Martins (2015) analisam os impactos do direcionamento ao nível das firmas, buscando identificar quais firmas se beneficiaram da expansão do crédito direcionado após a crise de 2008 no Brasil. Encontra-se que os maiores beneficiados pelos programas foram as empresas antigas, grandes e avessas ao risco. Além de tais firmas serem capazes de obter crédito a taxas de juros mais altas no mercado privado, o acesso às menores taxas presentes nas linhas de crédito direcionado não se traduz em aumento de investimento por parte delas, mas sim em uma maior lucratividade. Lazzarini et al. (2014) também examinam o processo de concessão de crédito pelo BNDES. Seus resultados indicam que o BNDES seleciona firmas com alta capacidade de repagamento, assim como o sistema bancário privado. No entanto, há indício de favorecimento a empresas com maior conexão política (medida pela contribuição a campanhas eleitorais) 
Efeitos de equilíbrio geral, como os aqui considerados, também já foram avaliados na literatura sobre o caso brasileiro. Souza-Sobrinho (2010) utiliza um modelo de agente representativo para analisar a variação do bem-estar que ocorreria após o encerramento dos programas de direcionamento. Conclui-se que o fim dos programas de direcionamento levaria a uma diminuição de juros aos investidores e ganhos de bem-estar da ordem de $2 \%$ do consumo corrente. O trabalho mais próximo deste artigo é o de Antunes, Cavalcanti e Villamil (2015), que acrescentam heteorgeneidade entre agentes à análise. Em seu modelo dinâmico de equilíbrio geral com restrilções de crédito, há um custo fixo de setup para se contratar crédito direcionado. Seus resultados não indicam efeitos quantitativos significativos sobre o produto per capita, mas apontam para efeitos negativos sobre salários, desigualade e finanças públicas. Nosso artigo contibui a esta literatura ao impor maior heterogeneidade e flexibilidade à análise, o que permite aderência a um rico conjunto de dados e maior riqueza nos exercícios contrafatuais.

Além desta introdução, o trabalho contém 5 seções. A seção 2 descreve o ambiente institucional do crédito direcionado no Brasil. A seção 3 descreve o modelo, define o equilíbrio, e apresenta o método de solução do modelo. Na seção 4 o modelo é calibrado. Na seção 5 são realizados exercícios contrafactuais por meio da alteração dos parâmetros da política de crédito. Por último, a seção 6 apresenta as conclusões do trabalho. 


\section{O Crédito Direcionado no Brasil}

O mercado de crédito bancário brasileiro apresenta uma combinação única de forte intervensionismo estatal e rica disponibilidade de dados que gera oportunidades promissoras de se estudar os efeitos de políticas públicas sobre os mercados financeiro e a economia. Há expressiva participação de bancos públicos e de direcionamento de crédito. Conforme mostra a figura 1, em 2007 o crédito direcionado correspondia a cerca de um terço do mercado de crédito brasileiro. Após a crise de 2008, sua participação cresceu e em 2015 ele já respondia por aproximadamente metade do mercado de crédito bancário do Brasil.

Figura 1 - Saldo de crédito livre e direcionado como \% do Total

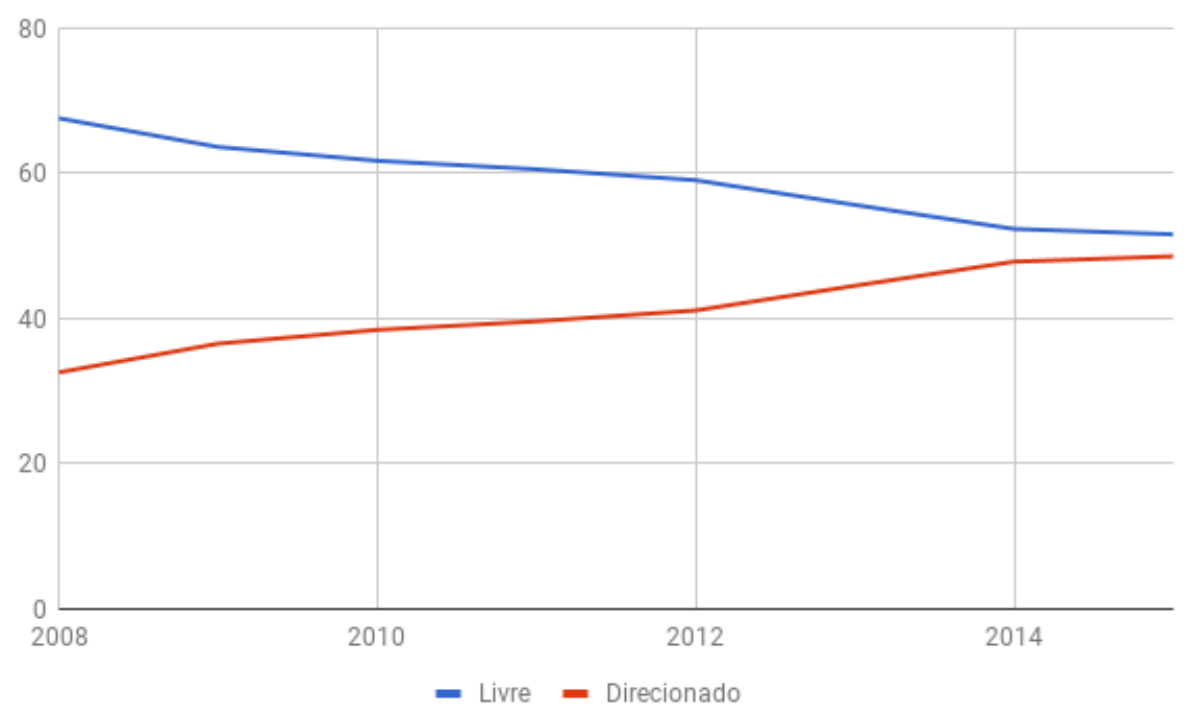

Fonte: Banco Central, elaboração própria.

A maior parte do crédito direcionado, cerca de 70\%, tem recursos originários do BNDES (Banco Nacional de Desenvolvimento Econômico e Social), conforme mostram Pazarbasioglu-Dutz et al. (2017). O BNDES é um banco de fomento do governo federal, cuja principal função é conceder crédito para financiar projetos das firmas nacionais e internacionais. As principais fontes de recurso do BNDES são o FAT (Fundo de Amparo ao Trabalhador) e o Tesouro Nacional. O FAT consiste em um fundo que recebe a poupança forçada dos trabalhadores, coletada por meio de imposto cobrado sobre a folha salarial. Já o financiamento por meio do Tesouro Nacional ocorre por meio de emissão de dívida pelo 
governo federal. A figura 2 mostra a composição das fontes de recurso do BNDES entre 2011 e $2017 .{ }^{1}$.

Figura 2 - Fontes de recurso do BNDES (em pontos percentuais)

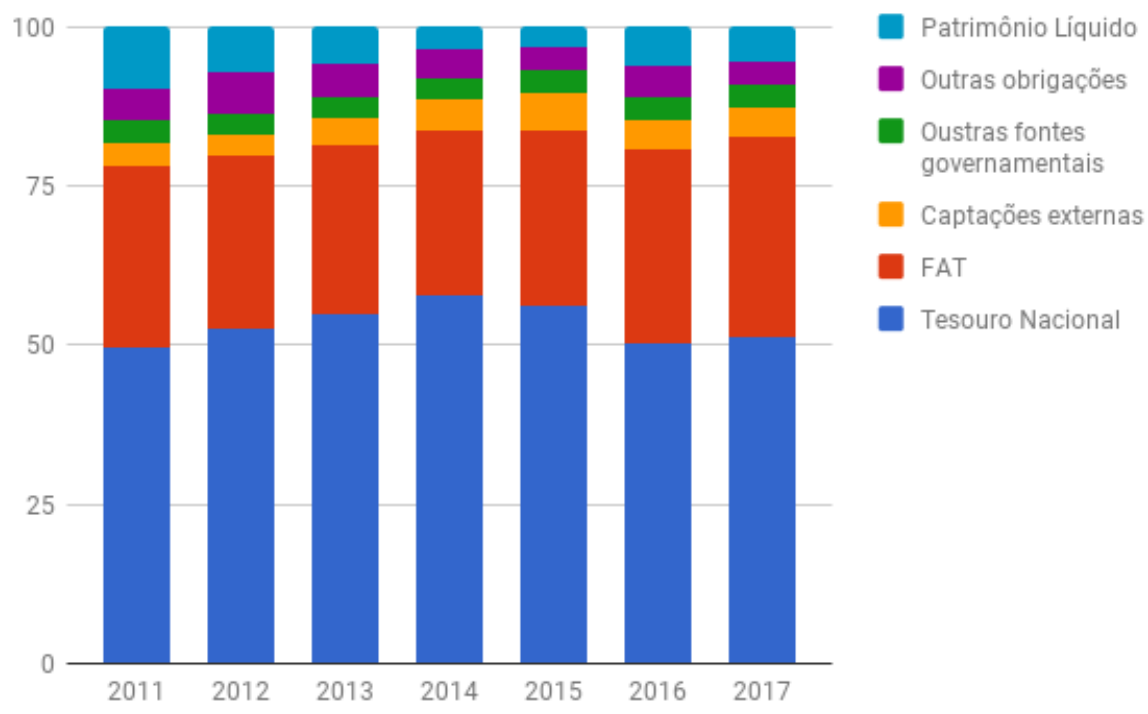

Fonte: BNDES, elaboração própria.

Nota-se que, nos últimos anos, o Tesouro Nacional responde por cerca da metade dos recurso do BNDES e o FAT por cerca de 30\%. Como tanto o FAT como o Tesouro são remunerados pelo BNDES segundo a TJLP (Taxa de Juros de Longo Prazo), uma taxa inferior às taxas de mercado, há um subsídio implícito nos empréstimos do banco, que recai, em sua maior parte, sobre o conjunto dos contribuintes e trabalhadores formais. ${ }^{2}$

O BNDES concede crédito para firmas de duas formas: por meio de operações diretas e indiretas. Cerca de metade do crédito concedido pelo BNDES se dá por meio das operações diretas ${ }^{3}$. Nestas operações, as empresas negociam diretamente com o banco de fomento os prazos, as taxas de juros e os demais termos do contrato. Vale notar que as empresas que acessam o crédito direcionado desta forma estão entre as maiores do país. Já nas operações indiretas, o BNDES utiliza o sistema financeiro nacional como uma forma de contornar sua dificuldade de chegar aos clientes, devido à ausência de agências próprias. Nesta modalidade, agentes financeiros autorizados se encarregam de encontrar os clientes

1 Dados disponíveis nos Relatórios Anuais do BNDES

2 A Taxa de Juros de Longo Prazo - TJLP foi instituída pela Medida Provisória no ${ }^{\circ}$ 684, de 31.10.94, publicada no Diário Oficial da União em 03.11.94, sendo definida como o custo básico dos financiamentos concedidos pelo BNDES.A TJLP é fixada pelo Conselho Monetário Nacional e divulgada até o último dia útil do trimestre imediatamente anterior ao de sua vigência.

3 Dado disponível no Sistema Gerenciador de Séries Temporais (SGS) do Banco Central do Brasil. 
elegíveis ao crédito direcionado. O BNDES repassa os recursos para o agente financeiro que assume o risco da operação e fica obrigado a remunerar o banco de fomento segundo a TJLP. Nestas operações, o agente financeiro tem liberdade para selecionar os clientes e fica livre para negociar a taxa de juros e os demais termos do contrato. Dessa forma, o crédito direcionado concedido por meio de operações indiretas cria uma taxa de captação alternativa no sistema financeiro. Apesar de responder por metade do volume do crédito concedido pelo BNDES, as operações indiretas são cerca de $97 \%$ das número de total de operações ${ }^{4}$.

Para construirmos nossa análise sobre os impactos do direcionamento de crédito, usamos informações referentes ao ano de $2012{ }^{5}$ de duas bases de dados à disposição do BCB. A primeira é o Sistema de Informações de Crédito (SCR), do Banco Central do Brasil, que reune todas as informações a respeito dos contratos de crédito de clientes com saldo devedor superior a mil reais em algum banco. A segunda é o Relatório Anual de Informações (RAIS), produzida pelo Ministério do Trabalho e Previdência Social, que possui informações sobre emprego e salários em cada firma. As duas bases foram fundidas pelo BCB, gerando uma nova base que permite observar as decisões de saldo de crédito em conjunto com o número de trabalhadores contratados de um total de 2.594.208 firmas formais.

A tabela 1 mostra a distribuição de tamanho das firmas, com maior prevalência de micro e pequenas empresas ${ }^{6}$. Note-se que são contabilizadas todas as firmas que estão reportadas na RAIS, mesmo que elas não tenham registro no $\mathrm{SCR}^{7}$.

4 A grande disparidade entre participação de repasses no número de operações e no volume total de empréstimos resulta do fato de que o montante médio emprestado por operação direta do BNDES é muito maior que o montante médio emprestado em repasses

5 O BCB dispõe de dados mais recentes, mas optamos por ajustar o modelo a um período de relativa estabilidade, anterior à recessão que se iniciou em 2013.

6 Curiosamente, há um número semelhante de firmas médias e grandes . A princípio, espera-se que a quantidade de firmas grandes seja significativamente menor que o número de firmas médias. Tal fato pode ocorrer devido ao critério utilizado para definir o tamanho da firma ser o número de trabalhadores contratados. Caso se adotasse um critério de faturamento, possivelmente tal idiossincrasia desaparecesse.

7 A definição utilizada para caracterizar o tamanho das firmas é a utilizada pelo IBGE (Instituto Brasileiro de Geografia e Estatística) para o setor de comércio e serviços 
Tabela 1 - Distribuição do tamanho das firmas

\begin{tabular}{cc}
\hline Tamanho da firma & Proporção no total de firmas \\
\hline \hline Micro & 0.805 \\
\hline Pequenas & 0.161 \\
\hline Médias & 0.017 \\
\hline Grandes & 0.017 \\
\hline
\end{tabular}

Fonte: Banco Central, elaboração própria.

Tabela 2 - Distribuição das formas de financiamento

\begin{tabular}{cc}
\hline Forma de financiamento & Proporção no total de firmas \\
\hline \hline Não utilizam crédito bancário & 0.492 \\
\hline Utilizam apenas crédito livre & 0.327 \\
\hline Utilizam apenas crédito direcionado & 0.018 \\
\hline Utilizam crédito livre e direcionado & 0.163 \\
\hline
\end{tabular}

Fonte: Banco Central, elaboração própria.

A tabela 2, apresenta a distribuição das formas de financiamento das firmas: ${ }^{8}$. Nota-se que cerca de metade das firmas está fora do mercado formal de crédito bancário, provavelmente dependendo de autofinanciamento para viabilizar investimentos. Outro destaque é que a grande maioria (cerca de 90\%) das firmas que tomam crédito direcionado também tomam crédito livre, o que indica uma grande complementariedade entre crédito direcionado e livre. Estes resultados sugerem que, ao tomar crédito, empresas com acesso a direcionamento contratam na verdade um "pacote", que combina crédito direcionado e livre. Tal padrão mantém-se constante por tamanho de firma, conforme revela a figura 3.

8 Aqui supomos que as firmas que estão na RAIS e não estão no SCR são as firmas que não utilizam o mercado de crédito 
Figura 3 - Distribuição das formas de financiamento por tamanho das firmas

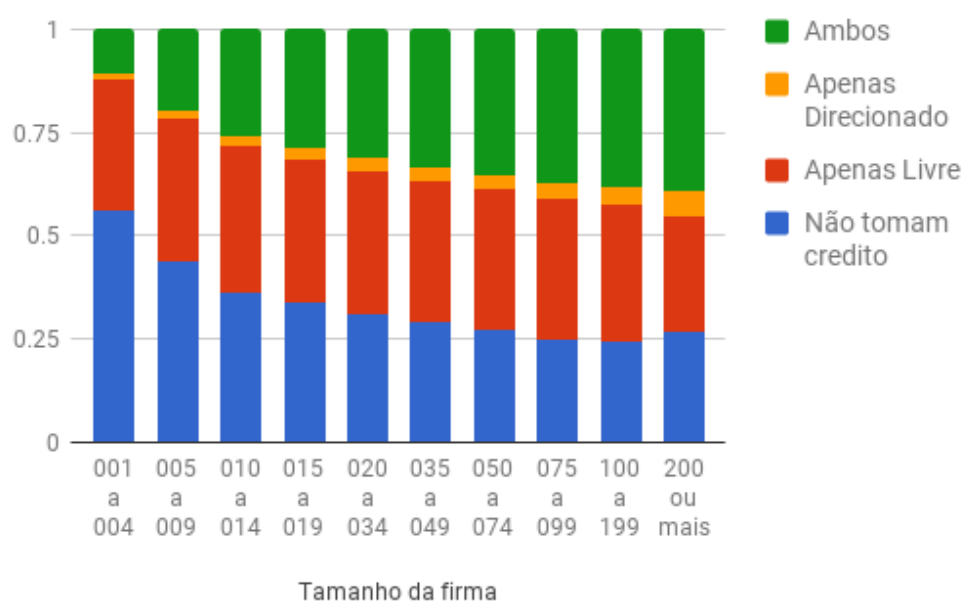

Fonte: Banco Central, elaboração própria.

A figura 4 mostra a composição do crédito das firmas que tomam tanto crédito direcionado quanto crédito livre por intervalos de tamanho medido em número de trabalhadores. Observa-se que, entre estas firmas, a composição entre crédito livre e crédito direcionado se mantém relativamente constante em todos os estratos de tamanho.

Figura 4 - Composição do crédito das firmas que utilizam crédito livre e direcionado

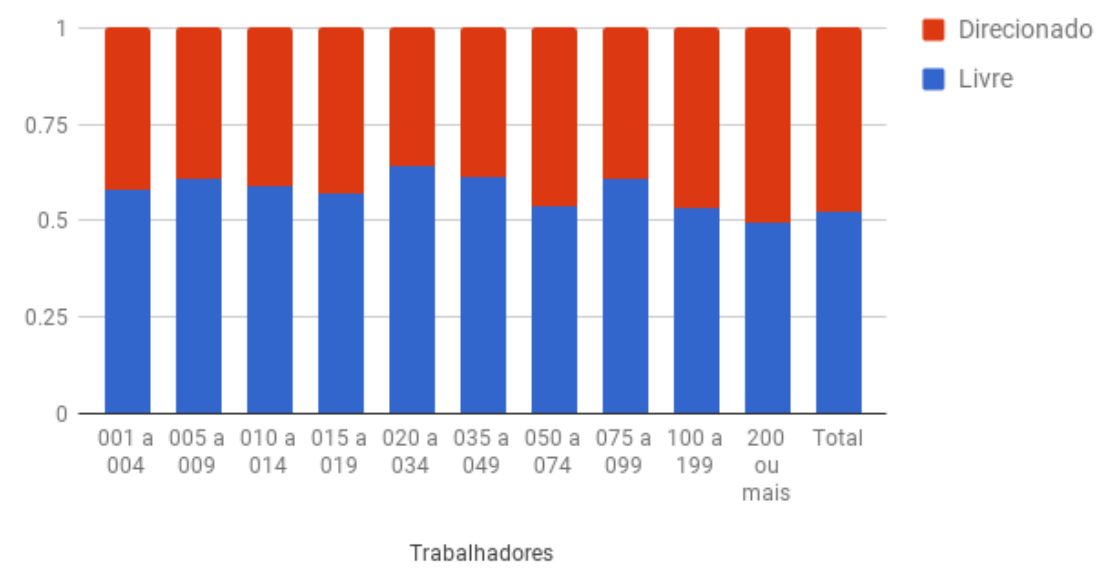

Fonte: Banco Central, elaboração própria.

Não só o acesso ao crédito livre está relacionado com o acesso ao crédito direcionado como a quantidade de crédito consumido aumenta consideravelmente quando a firma utiliza 
o crédito direcionado. As firmas com acesso ao direcionado, que correspondem a 18,1\% do total de firmas, são responsáveis pelo consumo de $81,2 \%$ do crédito da economia e de $67 \%$ do total de crédito livre.

O uso conjunto de crédito livre e direcionado pode estar relacionado ao fato de as duas modalidades, do ponto de vista da firma devedora, cumprirem papeis distintos. Como detalha Pazarbasioglu-Dutz et al. (2017) existe uma forte complementaridade entre crédito direcionado e livre, sendo que o primeiro é majoritariamente usado para investimento e o último para capital de giro. Além disso, nas operações de crédito direto do BNDES existe um limite do investimento que pode ser financiado pelo banco, o que pode gerar a necessidade das firmas recorrem ao crédito livre para realizar o projeto. Algo similar pode ocorrer nos bancos privados que fazem repasses de recursos do BNDES. É plausível inclusive supor que bancos privados condicionem o acesso a linhas subsidiadas pelo BNDES à contratação de outras linhas não subsidiadas. Este uso combinado de crédito livre e direcionado cumprirá um papel importante em nossa análise 


\section{O Modelo}

Nesta seção apresentamos um modelo que visa reproduzir as características do mercado de crédito brasileiro observadas nos dados. Trata-se de um modelo de equilíbrio geral com agentes heterogêneos num ambiente de mercados incompletos e risco idiossincrático de renda em tempo contínuo ${ }^{1}$. Recentes avanços matemáticos e computacionais tornaram tal classe de modelos consideravelmente mais tratável ${ }^{2}$. Cabe destacar o trabalho de Achdou et al. (2017), que desenvolve um conjunto de ferramentas para análise e solução numérica dessa classe de modelos com fricções no mercado de crédito.

Os agentes são heterogêneos em três dimensões: riqueza, produtividade e acesso ao crédito direcionado, sendo que a produtividade e o acesso ao direcionado evoluem de forma estocástica ao longo do tempo. A escolha ocupacional é endógena, seguindo a formulação de Lucas (1978). No mercado de financeiro, há restrição de crédito que será introduzida em uma formulação inspirada em Banerjee e Duflo (2010).

\subsection{A estrutura do Modelo}

Seguindo Achdou et al. (2017), o tempo é contínuo. Existe um contínuo de agentes com massa um e que são heterogêneos em três dimensões: riqueza, $a$, produtividade, $z$, e acesso ao crédito direcionado, e. A distribuição conjunta destas três variáveis, $g_{e}(a, z)$, caracteriza o conjunto de indivíduos dessa economia.

Para cada indivíduo, a produtividade evolui de acordo com um processo de difusão de Ito:

$$
d \ln z_{t}=-\kappa \ln z_{t} d t+\sigma d W_{t},
$$

de forma que $z_{t}$ tem uma distribuição estacionária log-normal.

O acesso ao crédito direcionado por um indivíduo é sumarizado pela variável $e$. Se $e=0$, o indivíduo não possui acesso ao crédito direcionado e se $e=1$, ele possui.

1 Para uma descrição mais completa dessa classe de modelos, ver Ríos-Rull (1995), Krusell e Smith (2006) e Ljungqvist e Sargent (2012).

2 Lasry e Lions (2007) fazem um sumário dessas novas técnicas e caracterizam esse novo campo de pesquisa, chamado de mean-field games, que busca entender o comportamento estratégico de um grande número de agentes racionais agindo de forma estratégica em ambientes de informação limitada. 
A variável e evolui de acordo com um processo de Poisson de dois estágios, de forma que $e$ passa de 0 para 1 com intensidade $\phi_{0}$ e de 1 para 0 com intensidade $\phi_{1}$. Ou seja, cada indivíduo pode transitar entre períodos de elegibilidade ou não a crédito direcionado conforme a a realização de eventos de entrada e saída que se ocorrem de acordo com distribuições Poisson. Os parametros destas distribuições, a princípio, podem depender de condicionantes como produtividade e riqueza

Em cada período, os indivíduos escolhem entre ser trabalhadores ou empresários. Se eles decidem ser trabalhadores, recebem $w z$ como salário. Se eles escolhem ser empresários, devem contratar trabalho e capital em mercados competitivos e produzir o único bem de consumo da economia segundo a função de produção:

$$
y=z\left(k^{\alpha} l^{\beta}\right)^{\theta}
$$

sendo $k$ e $l$, respectivamente, os montantes de capital e trabalho empregados, $\alpha$ e $\beta$ parâmetros que somam 1 e $\theta$ um parámetro positivo e inferior a 1 de span of control (conforme Lucas (1978)), que impõe concavidade à função de produção, permitindo lucro econômico positivo.

Existe um banco representativo que realiza empréstimos de crédito livre e direcionado. O custo marginal de captação de recursos livres deste banco é dado pela taxa de poupança, $r$, que é detarminada no equilíbrio competitivo que será descrito mais adiante. Porém, o banco pode captar recursos para utilizar no mercado de crédito direcionado à taxa $d$, sendo $d<r$. A diferença entre $d$ e $r$ é financiada pelo governo por meio de um imposto sobre a renda. Assim, o custo dos programas de direcionamento recai tanto sobre os trabalhadores quanto sobre os empresários ${ }^{3}$

O banco representativo oferece duas linhas de crédito. Uma de crédito livre e outra de crédito direcionado. Em cada uma dessas linhas, o banco cobra da firma devedora um markup sobre o custo incorrido. A inclusão deste markup no modelo é importante para que haja um bom ajuste aos dados, dada a alta magnitude dos spreads bancários no Brasil 4. Este markup representa tanto custos de concessão de crédito (como, por exemplo, os associados a reservas bancárias, tributos ou custos judicial e regulatório) quanto poder de mercado dos bancos em um ambiente de concorrência imperfeita. Por simplicidade, optamos por não considerar potenciais efeitos do direcionamento sobre este parâmetro de

3 Esta formulação inspira-se no fato de o BNDES ser responsável pela maior parte do crédito direcionado para as firma e sua principal fonte de recursos ser o Tesouro Nacional.

4 Estes spreads dificilmente poderiam ser explicados pelo direcionamento de crédito, uma vez que a maior parte dos subsídios a direcionamento é resultante de tributos e contribuições, e não subsídios cruzados dentro do sistema bancário. 
markup e o tomamos como exógeno.

Levando-se em conta que as firmas que tomam crédito direcionado tipicamente também tomam crédito livre (em nossa amostra, apenas $1.8 \%$ das firmas financiam-se somente com crédito direcionado), tratamos o crédito a firmas com acesso a crédito direcionado como um pacote com uma participação fixa de cada modalidade: $\varepsilon_{d}$ é a proporção de recursos direcionados e $\varepsilon_{l}$ a proporção de recursos livres. Assim, as taxas de juros de empréstimos às firmas que não recebem ou recebem direcionamento são, respectivamente, $r_{0}$ e $r_{1}$ definidos por:

$$
\begin{aligned}
& r_{0}=(1+\mu) r \\
& r_{1}=(1+\mu)\left(\varepsilon_{l} r+\varepsilon_{d} d\right),
\end{aligned}
$$

sendo $\mu$ o markup.

O banco representativo utiliza uma fração $\omega$ de seus recursos para criar os pacotes no mercado de crédito direcionado, sendo o restante disponibilizado para os empresários sem acesso ao direcionado. A ideia aqui é conseguir reproduzir, na etapa de calibração, o fato de que os indivíduos com acesso ao crédito respondem por $80 \%$ do consumo total de crédito.

Indivíduos estão sujeitos a um limite de endividamento resultante de comprometimento limitado. Este limite é dado por uma regra inspirada em Banerjee e Duflo (2010). Empreendedores podem evitar o pagamento dos empréstimos, caso paguem um custo $\eta a$, que pode ser interpretado como confisco de colateral. $\mathrm{O}$ banco, sabendo disso, só emprestará um volume de crédito compatível com a restrição de compatibilidade de incentivos:

$$
z\left(k^{\alpha} l^{\beta}\right)^{\theta}-w l-r a-r_{e}(k-a)-\delta k \geq z\left(k^{\alpha} l^{\beta}\right)^{\theta}-w l-r a-\eta a-\delta k,
$$

sendo $\delta$ a taxa de depreciação do capital.

Desta restrição, é possível derivar o máximo de capital que o empresário que utiliza o sistema financeiro poderá contratar em função da taxa de juros.

$$
k \leq \lambda_{e} a, \text { sendo } \lambda_{e}=1+\frac{\eta}{r_{e}}
$$

Note-se que o crédito direcionado não apenas diminui a taxa de juros para os indivíduos que o acessam, mas também flexibiliza a restrição de crédito de seus recipientes 
Nesta economia, assim como em Aiyagari (1994), toda riqueza assume a forma de capital produtivo. O empresário escolherá usar sua riqueza para se autofinanciar, caso exista a oportunidade, e recorrerá ao mercado de crédito quando suas necessidades de investimento superarem seus recursos próprios. Portanto, a demanda por capital da firma é dado por:

$$
k=\operatorname{Máx}\left\{k_{s}, k_{c}\right\},
$$

sendo $k_{c}$ é a solução do problema:

$$
\pi_{c}=\operatorname{Máx}_{k_{c}, l_{c}} z\left(k_{c}^{\alpha} l_{c}^{\beta}\right)^{\theta}-(r+\delta) a-\left(r_{e}+\delta\right)\left(k_{c}-a\right)-w l_{c} \text { sujeito a } k_{c} \leq \lambda_{e} a,
$$

e $k_{s}$ é dado pela solução do problema:

$$
\pi_{s}=\operatorname{Máx}_{k_{s}, l_{s}} z\left(k_{s}^{\alpha} l_{s}^{\beta}\right)^{\theta}-(r+\delta) k_{s}-w l_{s} \text { sujeito a } k_{s} \leq a \text {. }
$$

O indivíduo escolhe a ocupação que lhe dá a maior renda $M$ :

$$
M=(1-\tau) \operatorname{Máx}\{w z, \pi\},
$$

sendo $\tau$ é o imposto que incide sobre a renda e é usado para financiar o subsídio ao crédito direcionado, e $\pi=$ Máx $\left\{\pi_{s}, \pi_{c}\right\}$, o lucro derivado da atividade empresarial.

A riqueza dos indivíduos evolui de acordo com a seguinte equação:

$$
d a_{t}=\left(M_{t}+r a_{t}-c_{t}\right) d t
$$

Indivíduos são avessos a risco, com utilidade instantânea CES, e a cada instante decidem o quento consumir de maneira a maximizar a utilidade intertemporal, tomando como dados os preços e as trajetórias da riqueza, da produtividade e do acesso ao crédito direcionado. Resolvem, portanto, o problema:

$$
\begin{array}{ll}
\underset{c}{\operatorname{Máx}} & \int_{0}^{\infty} \mathrm{e}^{-\rho t} \frac{c_{t}^{1-\gamma}}{1-\gamma} d t \\
\text { sujeito a: } & d a_{t}=\left(M_{t}+r a_{t}-c_{t}\right) d t \\
& d z_{t}=\mu\left(z_{t}\right) d t+\sigma\left(z_{t}\right) d W_{t}, \\
& e_{t} \text { segue um processo de Poisson com dois estágios. }
\end{array}
$$


Conforme mostam Achdou et al. (2017) $)^{5}$, as decisões de consumo e poupança, assim como a evolução da distribuição conjunta que caracteriza a economia podem ser sumarizadas em duas equações diferenciais parciais: a Hamilton-Jacobi-Bellman (HJB) e a Kolgomorov Forward (KFE), dadas respectivamente por:

$$
\begin{aligned}
\rho V_{e}(a, z, t)= & \operatorname{Máx}_{c} u(c)+\partial_{a} V_{e}(a, z, t)[M+r(t) a-c]+\partial_{z} V_{e}(a, z, t) \mu(z)+ \\
& \frac{1}{2} \partial_{z z} V_{e}(a, z, t) \sigma^{2}(z)+\phi_{e}\left[V_{-e}(a, z, t)-V_{e}(a, z, t)\right]+\partial_{t} V_{e}(a, z, t) \\
\partial_{t} g_{e}(a, z, t)= & -\partial_{a}\left[s_{e}(a, z, t) g(a, z, t)\right]-\partial_{z}\left[\mu(z) g_{e}(a, z, t)\right]+\frac{1}{2} \partial_{z z}\left[\sigma^{2}(z) g_{e}(a, z, t)\right] \\
& -\phi_{e} g_{e}(a, z, t)+\phi_{-e} g_{-e}(a, z, t)
\end{aligned}
$$

A HJB corresponde a uma equação de Euler em tempo contínuo adaptada para considerar os processos estocásticos da produtividade e da elegibilidade ao direcionado. A KFE, por sua vez, determina a evolução das distribuições de tipos ao longo do tempo em função das decisões de poupança e consumo. Em um equilíbrio estacionário, tanto a função valor do problema do indivíduo quanto a distribuição conjunta dos indivíduos na economia não se alteram. Portanto, as versões estacionárias da HJB e da KFE são dadas por:

$$
\begin{aligned}
\rho V_{e}(a, z)= & \underset{c}{\operatorname{Máx}} u(c)+\partial_{a} V_{e}(a, z)[M+r a-c]+\partial_{z} V_{e}(a, z) \mu(z)+ \\
& \frac{1}{2} \partial_{z z} V_{e}(a, z) \sigma^{2}(z)+\phi_{e}\left[V_{-e}(a, z)-V_{e}(a, z)\right] \\
0= & -\partial_{a}\left[s_{e}(a, z) g_{e}(a, z)\right]-\partial_{z}\left[\mu(z) g_{e}(a, z)\right]+\frac{1}{2} \partial_{z z}\left[\sigma^{2}(z) g_{e}(a, z)\right] \\
& -\phi_{e} g_{e}(a, z)+\phi_{-e} g_{-e}(a, z)
\end{aligned}
$$

Sendo que a poupança, $s$, e o consumo, $c$, são dados por:

$$
s_{e}=M_{e}(a, z)+r a-c_{e}(a, z) ; c_{e}(a, z)=\left(u^{\prime}\right)^{-1}\left(\partial_{a} V_{e}(a, z)\right)
$$

Cabe destacar que, assim como em Aiyagari (1994), existe poupança precaucional. Os indivíduos acumularão mais riqueza no estado bom da natureza, e acumularão menos ou desacumularão, conforme pior for o estado da natureza em que se encontram. Tal fato fará com que a taxa de juros de equilíbrio seja menor do que o desconto intertemporal dos agentes ${ }^{6}$.

\footnotetext{
5 Ver apêndice para maiores detalhes

6 Ver derivação da equação de Euller no Apêndice A.
} 
O domínio das duas equações que caracterizam o equilíbrio de estado estacionário é dado por: $(\underline{a}, \infty) \times(\underline{z}, \bar{z})$.

Como $a \geq \underline{a}$, é preciso ter $s_{e}(\underline{a}, z) \geq 0$, o que dá origem à seguinte condição de fronteira:

$$
u^{\prime}(M+r \underline{a}) \geq \partial_{a} V_{e}(\underline{a}, z), \forall z, s=0,1
$$

Além disso, como o processo de difusão da produtividade está refletido entre $\underline{z}$ e $\bar{z}$, $V_{e}$ deve satisfazer também a condição de fronteira abaixo: ${ }^{7}$

$$
\partial_{z} V_{e}(a, \underline{z})=0, \partial_{z} V_{e}(a, \bar{z})=0, \forall a, s=0,1
$$

Por último, para caracterizar o equilíbrio estacionário do modelo, os mercados de crédito direcionado, de crédito livre e de trabalho devem estar em equilíbrio, assim como o montante de subsídio ao crédito direcionado deve ser igual à arrecadação tributária. Para tanto, é preciso fazer a distinção entre riqueza no sistema financeiro $a_{f}$ e a riqueza usada para o autofinanciamento $a_{s}$, sendo que $a=a_{f}+a_{s}$. Em outras palavras, sendo $k^{e}$ e $l^{e}$ as demandas por capital e trabalho do indivíduo cujo estado de acesso ao direcionado é $e$, as condições abaixo devem ser respeitadas:

\section{Equilíbrio no mercado de crédito direcionado:}

$\int_{\underline{z}}^{\bar{z}} \int_{\underline{a}}^{\infty} \operatorname{Máx}\left\{k^{1}-a, 0\right\} g_{1}(a, z) d a d z \mathbb{1}_{\{\pi \geq(1-\tau) w z\}}-\omega\left[\int_{\underline{z}}^{\bar{z}} \int_{\underline{a}}^{\infty} a_{f} g_{0}(a, z) d a d z+\int_{\underline{z}}^{\bar{z}} \int_{\underline{a}}^{\infty} a_{f} g_{1}(a, z) d a d z\right]=0$

O primeiro termo consiste na demanda de crédito das firmas com acesso ao crédito direcionado e o segundo termo corresponde a fração da riqueza no sistema financeiro destinada aos indivíduos que acessam o direcionado.

\section{Equilíbrio no mercado de crédito livre:}

$$
\begin{aligned}
& \int_{\underline{z}}^{\bar{z}} \int_{\underline{a}}^{\infty} \operatorname{Máx}\left\{k^{0}-a, 0\right\} g_{0}(a, z) d a d z \mathbb{1}_{\{\pi \geq(1-\tau) w z\}} \\
& -(1-\omega)\left[\int_{\underline{z}}^{\bar{z}} \int_{\underline{a}}^{\infty} a_{f} g_{0}(a, z) d a d z+\int_{\underline{z}}^{\bar{z}} \int_{\underline{a}}^{\infty} a_{f} g_{1}(a, z) d a d z\right]=0
\end{aligned}
$$

\footnotetext{
7 Ver seção 3.5 em Dixit (1993)
} 
O primeiro termo consiste na demanda de crédito das firmas sem acesso ao crédito livre e o segundo termo corresponde a fração da riqueza no sistema financeiro destinada aos indivíduos que não acessam o direcionado.

\section{Equilíbrio no mercado de trabalho:}

$$
\begin{aligned}
& \int_{\underline{z}}^{\bar{z}} \int_{\underline{a}}^{\infty} l^{0} g_{0}(a, z) d a d z \mathbb{1}_{\{\pi \geq(1-\tau) w z\}}+\int_{\underline{z}}^{\bar{z}} \int_{\underline{a}}^{\infty} l^{1} g_{1}(a, z) d a d z \mathbb{1}_{\{\pi \geq(1-\tau) w z\}} \\
& -\int_{\underline{z}}^{\underline{z}} \int_{\underline{a}}^{\infty} z g_{0}(a, z) d a d z \mathbb{1}_{\{\pi<(1-\tau) w z\}}-\int_{\underline{z}}^{\infty} \int_{\underline{a}}^{\infty} z g_{1}(a, z) d a d z \mathbb{1}_{\{\pi<(1-\tau) w z\}}=0
\end{aligned}
$$

O primeiro e o segundo termo são, respectivamente, a demanda por trabalho por parte das firmas sem acesso e das com acesso ao direcionado. Já os dois últimos termos são a oferta de trabalho por parte das famílias.

\section{Financiamento do crédito direcionado:}

$$
\begin{aligned}
& \tau\left[\int_{\underline{z}}^{\bar{z}} \int_{\underline{a}}^{\infty} M g_{0}(a, z) d a d z+\int_{\underline{z}}^{\bar{z}} \int_{\underline{a}}^{\infty} M g_{1}(a, z) d a d z\right] \\
& -\varepsilon_{d}(r-d)\left[\int_{\underline{z}} \int_{\underline{a}}^{\infty} \operatorname{Máx}\left\{k^{1}-a, 0\right\} g_{1}(a, z) d a d z \mathbb{1}_{\{\pi \geq(1-\tau) w z\}}\right]=0
\end{aligned}
$$

O primeiro termo corresponde à arrecadação do imposto sobre a renda e o segundo termo é o custo do subsídio dado ao crédito direcionado.

\subsection{Solução do Modelo}

Nesta seção será feita uma apresentação sintética do método de resolução do modelo apresentado. Para maiores informações, ver apêndice.

Utiliza-se o método de diferenças finitas para computar a solução da HJB. Tal método aproxima a função $V_{e}$ em $I$ pontos na dimensão $a$ (definindo assim os valores $a_{i}$, com $i=1, \ldots, I$, sendo $\Delta a$ a distância entre os pontos do grid) e $J$ pontos na dimensão de $z$, (definindo similarmente os valores $z_{j}$, com $j=1, \ldots, J$, sendo $\Delta z$ a distância entre os pontos desse grid). Adotamos a notação $V_{e, i, j} \equiv V_{e}\left(a_{i}, z_{j}\right)$. 
Utilizamos então a seguinte aproximação discreta de (3.14):

$$
\begin{aligned}
& \frac{V_{e, i, j}^{n+1}-V_{e, i, j}^{n}}{\Delta}+\rho V_{e, i, j}^{n+1}-u\left(c_{e, i, j}^{n}\right)-\partial_{a} V_{e, i, j}^{n+1}\left[M_{e, i, j}^{n}+r a_{i}-c_{e, i, j}^{n}\right]-\mu_{j} \partial_{z} V_{e, i, j}^{n+1} \\
& -\frac{1}{2} \sigma_{j}^{2} \partial_{z z} V_{e, i, j}^{n+1}-\phi_{e}\left(V_{-s, i, j}^{n+1}-V_{e, i, j}^{n+1}\right)=0
\end{aligned}
$$

Tal estratégia é dita implícita, devido ao fato de $V_{e}^{n+1}$ estar implicitamente definida pela equação acima. O parâmetro $\Delta$ é o step size do método de diferenças finitas. A vantagem de utilizar a versão implícita do método de diferenças finitas, como mostra Candler et al. (1998), é que a solução de (3.23) convergirá para a solução de (3.14) independente do tamanho de $\Delta .^{8}$

Podemos aproximar as derivadas da equação acima tanto pela diferença para frente como pela diferença para trás.

As derivadas em relação a $z$ serão aproximadas por diferenças para frente:

$$
\partial_{z} V_{e, i, j, F} \simeq \frac{V_{e, i, j+1}-V_{e, i, j}}{\Delta a}, \partial_{z z} V_{e, i, j, F} \simeq \frac{V_{e, i, j+1}-2 V_{e, i, j}+V_{e, i, j-1}}{(\Delta z)^{2}}
$$

Já as derivadas em relação a a serão aproximadas pelo Upwind Scheme, que consiste em usar a diferença para trás quando a poupança for negativa e a diferença para frente quando a poupança for positiva, assim:

$$
\partial_{a} V_{e, i, j, F} \simeq \frac{V_{e, i+1, j}-V_{e, i, j}}{\Delta a}, \partial_{a} V_{e, i, j, B} \simeq \frac{V_{e, i, j}-V_{e, i-1, j}}{\Delta a}
$$

Tal artifício é necessário para que as condições descritas por Barles e Souganidis (1991), que garantem a convergência da solução do método de diferenças finitas para a única solução de viscosidade de (3.14), sejam respeitadas. Outra vantegem deste método de aproximação é que ele se encarrega de garantir que a condição de fronteira da dimensão $a$ não seja desrespeitada no interior do espaço de estado ${ }^{9}$.

8 A versão explícita do esquema numérico dada por:

$\frac{V_{e, i, j}^{n+1}-V_{e, i, j}^{n}}{\Delta}+\rho V_{e, i, j}^{n}-u\left(c_{e, i, j}^{n}\right)-\partial_{a} V_{e, i, j}^{n}\left[M_{e, i, j}^{n}+r a_{i}-c_{e, i, j}^{n}\right]-\mu_{j} \partial_{z} V_{e, i, j}^{n}-\frac{1}{2} \sigma_{j}^{2} \partial_{z z} V_{e, i, j}^{n}-\phi_{e}\left(V_{-s, i, j}^{n}-V_{e, i, j}^{n}\right)=0$

converge apenas para valores não muito grandes de $\Delta$, sendo que $\Delta$ tem que satisfazer as condições CFL para que a convergência seja garantida.

9 Ver capítulo 5 Achdou et al. (2017) 
Dessa forma, o nosso esquema numérico é dado por:

$$
\begin{aligned}
\frac{V_{e, i, j}^{n+1}-V_{e, i, j}^{n}}{\Delta}+\rho V_{e, i, j}^{n+1}= & u\left(c_{e, i, j}^{n}\right)+\frac{V_{e, i+1, j}^{n+1}-V_{e, i, j}^{n+1}}{\Delta a}\left[s_{e, i, j}^{n} F\right]^{+}+\frac{V_{e, i, j}^{n+1}-V_{e, i-1, j}^{n+1}}{\Delta a}\left[s_{e, i, j}^{n} B\right]^{-} \\
& +\mu_{j}\left[\frac{V_{e, i, j+1}^{n+1}-V_{e, i, j}^{n+1}}{\Delta z}\right]+\frac{1}{2} \sigma_{j}^{2}\left[\frac{V_{e, i, j+1}^{n+1}-2 V_{e, i, j}^{n+1}+V_{e, i, j-1}^{n+1}}{(\Delta z)^{2}}\right] \\
& +\phi_{e}\left(V_{-s, i, j}^{n+1}-V_{e, i, j}^{n+1}\right)
\end{aligned}
$$

Tal sistema consiste em $I \times J \times 2$ equações lineares. Em notação matricial:

$$
\frac{1}{\Delta}\left(V^{n+1}-V^{n}\right)+\rho V^{n+1}=u^{n}+A^{n} V^{n+1}
$$

Note que quando $\left(V^{n+1}-V^{n}\right)=0$ :

$$
\rho V^{n+1}=u^{n}+A^{n} V^{n+1}
$$

Basicamente, o método de diferenças finitas aproxima a dinâmica do modelo por um processo discreto Poisson com $I \times J \times 2$ estados, sendo $A^{n}$ uma matriz de transição de Poisson que descreve a evolução do processo estocástico de $\left(a_{t}, z_{t}, e_{t}\right)$, podendo ainda ser interpretada como a versão discretizada do operador diferencial da HJB.

Reorganizando os termos em (3.27):

$$
B^{n} V^{n+1}=b^{n} \text {, sendo } B^{n}=\left(\frac{1}{\Delta}+\rho\right) I-A^{n}, b^{n}=u^{n}+\frac{1}{\Delta} V^{n}
$$

Sendo que $B^{n}$ é altamente esparsa. Dessa forma, a HJB pode ser facilmente resolvida computacionalmente para o estado estacionário por métodos iterativos.

Para resolver a equação Kolgomorov Forward usa-se o fato de que seu operador diferencial é adjunto do operador diferencial da Hamilton-Jacobi-Bellman. Assim, a versão matricial discretizada de (3.15) é dada por:

$$
A^{T} g=0
$$

Onde $A^{T}$ é a transposta de $A^{n}$ da última iteração do processo de resolução da HJB. Tal sistema pode facilmente ser resolvido computacionalmente e tem como solução $g$ que descreve a distribuição de estado estacionário dos indivíduos dessa economia. 
Por último, para encontrar um equilíbrio que satisfaça as condições de zero excesso de demanda nos mercados e a condição de financiamento do crédito direcionado, é feito um palpite sobre os valores de $r, w, \tau$ e $\phi_{1}$. Em seguida, resolve-se a HJB e a KFE e calcula-se os excessos de demanda e o excesso de financiamento. Caso as condições sejam violadas, atualiza-se os palpites, resolvendo novamente a HJB e a KFE. Repete-se o procedimento até que o equilíbrio seja encontrado. 


\section{Calibração}

Em uma etapa preliminar, os valores de alguns parâmetros são escolhidos de acordo com os valores costumeiramente utilizados na literatura. com base em Gollin (2002), Os valor do share do capital na produção $(\alpha)$ será 0.4 , e o do share do trabalho na produção ( $\beta$ ) será 0.6. Já a depreciação será fixada em 0.04, baseado em Morandi, Reis et al. (2004).

Alguns outros parâmetros podem ser observados diretamente nos dados. O parâmetro $\omega$ é escolhido para reproduzir a proporção do crédito que é consumido pelas firmas que possuem acesso ao direcionado. Oa parâmetros $\varepsilon_{d}$ e $\varepsilon_{l}$ são escolhidos de acordo com a proporção entre crédito livre e direcionado da firma que toma crédito em ambos os mercados. Já o parâmetro $d$ é escolhido de acordo com a TJLP e a taxa de inflação do período. ${ }^{1}$

O parâmetro $\phi_{0}$ determina a probabilidade de um indivíduo passar a ser elegível a receber direcionamento. Esta probabilidade potencialmente depende de parâmetros como riqueza e produtividade. O direcionamento de crédito no Brasil ${ }^{2}$ é um complexo sistema de regras e decisões, com múltiplas linhas criadas e desativadas ao longo do tempo, operado em alguns casos diretamente pelo BNDES e em outras ocasiões por bancos privados que fazem repasses em função de projetos apresentados ao BNDES. Trata-se portanto de uma estrutura difícil de ser replicada fielmente. Lazzarini et al. (2014) encontram indícios de que influência política pode aumentar a probabilidade de obter empréstimos enquanto Bonomo, Brito e Martins (2015) encontram que firmas grandes tem maior probabilidade de serem beneficiadas. Isso poderia sugerir que indiviíduos mais ricos ou mais produtivos têm maior probabilidade de receber direcionamento. No entanto, há linhas específicas para pequenos empreendedores de baixa renda (como, por exemplo, as de microcrédito) e, conforme mostra a figura 3, há participação relevante de direcionamento no crédito mesmo entre as firmas de menor tamanho. Assim, em nossa especificação padrão, seremos agnósticos sobre estas relações, e suporemos que $\phi_{0}$ independe de riqueza e produtividade. Em um exercício posterior, examinaremos casos em que este parâmetro é dependente das características individuais.

Tomando-se como dada a fração de crédito direcionado $\omega$, o parâmetro $\phi_{0}$ está associado ao tempo médio que cada indivíduo permanece recebendo direcionamento. Um valor elevado de $\phi_{0}$ indica muita entrada de novos recipientes, e para que a fração de crédito direcionado mantenha-se em $\omega$, é necessário que sua permanencia seja curta. Não

1 Em dezembro de 2012, foi anunciado que a TJLP seria fixada em $5 \%$ e ela permaneceu com esse valor até 2015. Além disso, a inflação em 2012 foi de 5,84\%.

2 Ver, por exemplo Pazarbasioglu-Dutz et al. (2017) 
dispomos de dados sobre o tempo de permanência de cada firma como recipiente potencial de crédito direcionado, portanto consideramos em nossos exercícios um largo intervado de tempo médio de permanência, entre 2 e 11 anos. Em nossa especificação padrão, escolhemos $\phi_{0}$ tal que a permanência média seja de cerca de 7 anos. Exercícios de robustez mostram que mudanças neste parâmetro têm um efeito limitado sobre os resultados obtidos.

Tabela 3 - Calibração prévia: parâmetros observados nos dados

\begin{tabular}{cc}
\hline Parâmetro & Valor atribuído \\
\hline \hline Taxa de captação do direcionado $(d)$ & -0.0084 \\
\hline Fração do crédito destinado ao "pacote" de crédito $(\omega)$ & 0.812 \\
\hline Fração do "pacote" de crédito que é direcionado $\left(\varepsilon_{d}\right)$ & 0.45 \\
\hline Fração do "pacote" de crédito que é livre $\left(\varepsilon_{l}\right)$ & 0.55 \\
\hline Intensidade com que $e$ passa de 0 para 1 $\left(\phi_{0}\right)$ & 0.0015 \\
\hline
\end{tabular}

Fonte: Produzido pelo autor.

Por último, nesta etapa, serão escolhidos os limites e o número de pontos no grid computacional da riqueza e da produtividade:

Tabela 4 - Calibração prévia: parâmetros computacionais

\begin{tabular}{cc}
\hline Parâmetro & Valor atribuído \\
\hline \hline Produtividade máxima $(\bar{z})$ & 0.3 \\
\hline Produtividade mínima $(\underline{z})$ & 2.2 \\
\hline Número de pontos no grid de produtividade $(K)$ & 50 \\
\hline Riqueza máxima $(\bar{a})$ & 30000 \\
\hline Número de pontos no grid de riqueza $(I)$ & 0 \\
\hline
\end{tabular}

Fonte: Produzido pelo autor.

O número de pontos no grid é escolhido para que os resultados encontrados sejam estáveis quando aumentamos o número de pontos do grid e para a manter o problema computacionalmente tratável. Os limites da produtividade são iguais aos utilizados por Achdou et al. (2017). Na dimensão da riqueza, o limite inferior é escolhido para reproduzir a evidência empírica de que existe uma massa de indivíduos em torno de $a=0$ e o limite superior é escolhido para que nenhum indivíduo seja impedido de acumular riqueza.

Os demais parâmetros, sumarizados no vetor $\psi=(\gamma, \theta, \rho, \eta, \mu, \kappa, \sigma)$, serão escolhidos para minimizar a distância entre alguns momentos gerados pelo modelo e os momentos 
observados nos dados. Para tanto, serão utilizadas momentos das distribuições de formas de financiamento e de tamanho das firmas.

Da distribuição de formas de financiamento, serão utilizados como momentos: a fração de firmas que não utilizam crédito, que utilizam apenas crédito livre e que utilizam crédito direcionado, sendo que nos dados, este último momento é a soma da fração de firmas que utilizam apenas crédito direcionado e de firmas que utilizam crédito livre e direcionado. Já da distribuição de tamanho das firmas serão utilizados como momentos: as frações de micro firmas, de firmas pequenas, de firmas médias e de firmas grandes.

Os valores encontrados para os parâmetros de $\psi$ são apresentados a seguir:

Tabela 5 - Resultados da calibração

\begin{tabular}{cc}
\hline Parâmetro & Valor \\
\hline \hline Parâmetro da utilidade CRRA $(\gamma)$ & 2.0535 \\
\hline Intensidade dos retornos decrescentes $(\theta)$ & 0.8685 \\
\hline Desconto intertemporal $(\rho)$ & 0.0923 \\
\hline Parâmetro da restrição de crédito $(\eta)$ & 0.0312 \\
\hline Markup do sistema financeiro $(\mu)$ & 6.3715 \\
\hline Parâmetro do processo de difusão da produtividade $(\sigma)$ & 0.0918 \\
\hline Fonte: Produzido pelo autor.
\end{tabular}

Fonte: Produzido pelo autor.

Cabe comentar que o valor encontrado para $\mu$, apesar de alto, se enquadra na realidade brasileira, dado que em 2012 a taxa real de juros SELIC foi de $1.8 \%$ e a taxa de juros média em operações de crédito para pessoas jurídicas foi de $13.85 \%{ }^{3}{ }^{3}$

A seguir são apresentados os valores de equilíbrio de algumas variáveis de interesse:

3 Dados disponíveis no Sistema Gerenciador de Séries Temporais (SGS) do Banco Central do Brasil. 
Tabela 6 - Valores de estado estacionário de variáveis de interesse

\begin{tabular}{|c|c|}
\hline Variável & Valor \\
\hline Restrição de crédito dos indivíduos sem direcionado $\left(\lambda_{0}\right)$ & 1.3079 \\
\hline Restrição de crédito dos indivíduos com direcionado $\left(\lambda_{1}\right)$ & 2.1193 \\
\hline Taxa de remuneração da poupança $(r)$ & 0.0137 \\
\hline Taxa de juros cobrada dos indivíduos sem acesso ao crédito direcionado $\left(r_{0}\right)$ & 0.1014 \\
\hline Taxa de juros cobrada dos indivíduos com acesso ao crédito direcionado $\left(r_{1}\right)$ & 0.0279 \\
\hline Salário $(w)$ & 1.0410 \\
\hline Imposto sobre a renda $(\tau)$ & 0.0065 \\
\hline Intensidade com que $e$ passa de 1 para $0\left(\phi_{1}\right)$ & 0.0131 \\
\hline Fração de empresários na população & 0.0685 \\
\hline Gini da renda & 0.4254 \\
\hline Tempo médio de acesso ao crédito direcionado & 7.8417 \\
\hline
\end{tabular}

Fonte: Produzido pelo autor.

Vale destacar que o Índice de Gini em 2012 foi de 0.496, valor próximo ao gerado pelo modelo ${ }^{4}$. Além disto, o percentual de empregadores e trabalhadores por conta própria com registro no CNPJ (Cadastro Nacional de Pessoas Jurídicas) na PNAD (Pesquisa Nacional por Amostra de Domicílios) de 2012 foi de 4.4\%, valor não muito distante do gerado pelo modelo.

A próxima tabela mostra o ajuste do modelo às estatísticas utilizadas na tercerira etapa da calibração:

Tabela 7 - Ajuste do modelo aos dados

\begin{tabular}{ccc}
\hline Momento & Dados & Modelo \\
\hline \hline Fração de micro firmas & 0.805 & 0.8069 \\
\hline Fração de firmas pequenas & 0.161 & 0.1505 \\
\hline Fração de firmas médias & 0.017 & 0.0347 \\
\hline Fração de firmas grandes & 0.017 & 0.0079 \\
\hline Fração de firmas que não utilizam o mercado de crédito & 0.492 & 0.4929 \\
\hline Fração de firmas que utilizam apenas o crédito livre & 0.327 & 0.3276 \\
\hline Fração de firmas que utilizam o crédito direcionado & 0.181 & 0.1795 \\
\hline
\end{tabular}

Fonte: Produzido pelo autor.

$\overline{4}$ O valor do Índice de Gini utilizado foi calculado pelo IBGE com base na PNAD. 
Como pode ser verificado, o modelo se ajusta bem aos dados, tendo dificuldade de reproduzir apenas a cauda pesada da distribuição de tamanho das firmas ${ }^{5}$.

A distribuição de produtividade de estado estacionário e as funções poupança, do modelo calibrado, são apresentadas a seguir:

Figura 5 - Distribuição de produtividade

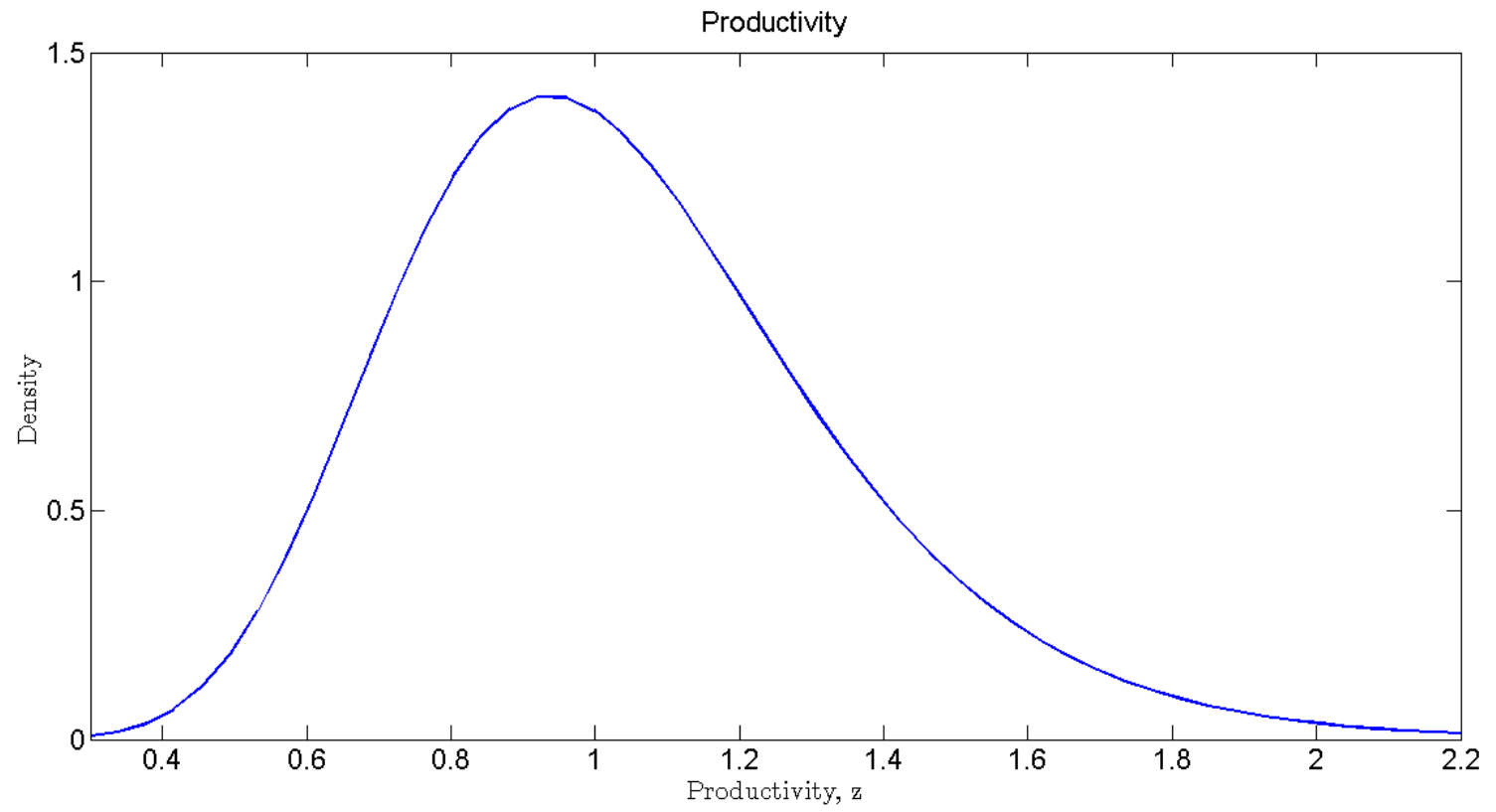

Fonte: Produzido pelo autor.

5 Os dados apresentam uma participação particularmente alta de firmas grandes. Trata-se de uma particularidade do caso brasileiro que não pode ser explicada por esse modelo. Uma possibilidade a ser estudada é que ela esteja associada a programas de incentivos com maior foco nestas empresas. 
Figura 6 - Funções poupança
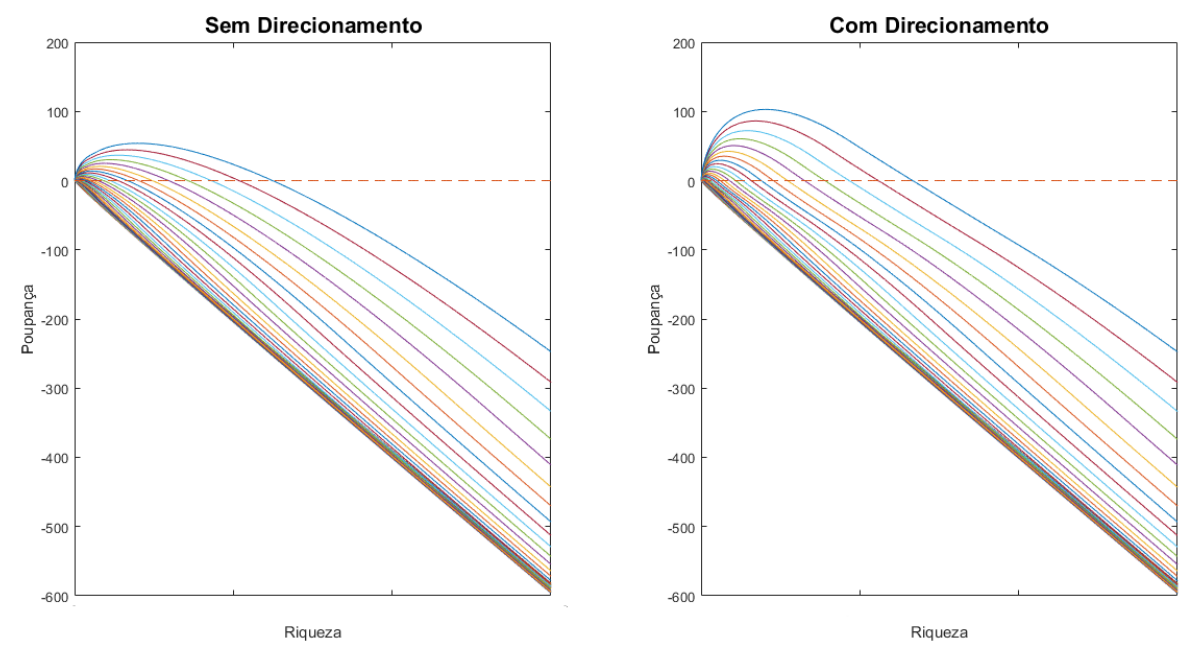

Fonte: Produzido pelo autor.

Como se pode observar, as condições de fronteira na dimensão de $z$ são respeitadas e toda massa de indivíduos está entre os limites de impostos a $z$.

Quanto à função poupança, cada linha no gráfico representa um valor do grid de produtividade, sendo que a intersecção da função poupança com o eixo $x$ é o nível máximo de riqueza que o indivíduo com aquela produtividade está disposto a carregar. É possível notar que indivíduos com maior produtividade poupam mais e estão dispostos a acumular um nível maior de riqueza. Além disto, indivíduos com acesso ao crédito direcionado possuem um maior nível ótimo de riqueza e o atingem mais rapidamente. Vale destacar que nenhum indivíduo é impedido de alcançar o nível desejado de riqueza ou é capaz de atingir níveis negativos de riqueza. 
Por último, será apresentada a distribuição de riqueza:

Figura 7 - Distribuição de riqueza

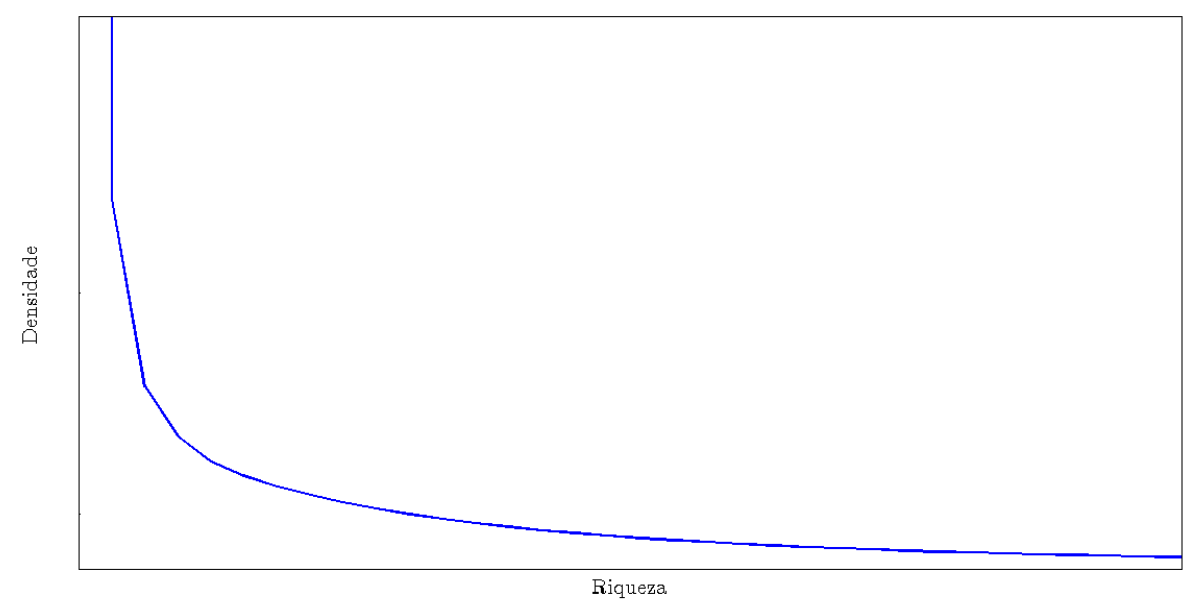

Fonte: Produzido pelo autor.

Note-se que ela apresenta uma cauda de Pareto, conforme o usual na literatura. 



\section{Exercícios Contrafactuais}

Nesta seção serão conduzidos exercícios contrafactuais utilizando o modelo anteriormente desenvolvido e calibrado. Em um primeiro momento, será analisado o que ocorre com a economia quando o crédito direcionado deixa de existir. Em seguida, serão analisadas os impactos de mudanças na forma como o crédito direcionado é distribuído.

\subsection{Extinção do programa de crédito direcionado}

Neste primeiro exercício, elimina-se o subsídio dado ao crédito direcionado, o que torna $d$ igual a $r$. A tributação sobre a renda deixa de existir e o salário e a taxa de juros se ajustam para reequilibrar os mercados de trabalho e capital, respectivamente. Todas as demais variáveis são mantidas constantes.

Dessa forma, a taxa de juros e a restrição de crédito passam a ser iguais para todos os indivíduos. Tal exercício assemelha-se à medida provisória que busca substituir a TJLP pela TLP (Taxa de Longo Prazo), com objetivo de eliminar progressivamente a diferença do custo de captação do crédito direcionado e do crédito livre. ${ }^{1}$

A seguir, apresenta-se a variação que ocorrre nas variáveis de interesse:

1 A Medida Provisória 777/2017, que regulamenta a nova taxa de juros do BNDES, a TLP, foi aprovada na câmara dos deputados no dia 30 de agosto de 2017 
Tabela 8 - Variação percentual após o fim do programa de direcionamento de crédito

\begin{tabular}{cccc}
\hline Variável & Antes & Depois & Variação percentual \\
\hline \hline Salário recebido pelo trabalhador & 1.0342 & 1.0574 & $2.24 \%$ \\
\hline Taxa de rendimento da poupança & 0.0137 & 0.0088 & $-38.8 \%$ \\
\hline Taxa de juros cobrada dos indivíduos sem acesso ao crédito direcionado & 0.1014 & 0.0650 & $-38.8 \%$ \\
\hline Taxa de juros cobrada dos indivíduos com acesso ao crédito direcionado & 0.0279 & 0.0650 & $132.97 \%$ \\
\hline Restrição de crédito dos indivíduos sem direcionado & 1.3079 & 1.4798 & $13.14 \%$ \\
\hline Restrição de crédito dos indivíduos com direcionado & 2.1193 & 1.4798 & $-30.18 \%$ \\
\hline Produto & 1.8801 & 1.8972 & $0.91 \%$ \\
\hline Demanda por capital & 6.1732 & 6.0518 & $-1.97 \%$ \\
\hline Fração de empresários na população & 0.0685 & 0.0725 & $5.84 \%$ \\
\hline Fração de firmas que não utilizam o mercado crédito & 0.4929 & 0.4188 & $-18.3 \%$ \\
\hline Fração de micro firmas & 0.8069 & 0.8168 & $1.23 \%$ \\
\hline Fração de firmas pequenas & 0.1505 & 0.1478 & $-1.72 \%$ \\
\hline Fração de firmas grandes & 0.0347 & 0.0313 & $-9.8 \%$ \\
\hline Gini renda & 0.0079 & 0.0042 & $-46.84 \%$ \\
\hline
\end{tabular}

Fonte: Produzido pelo autor.

Além disto, temos que a TFP aumenta em $1.63 \%^{2}$ e o bem-estar em $2.18 \%$. O cálculo da variação do bem-estar é feito neste, e nos demais exercícios contrafactuais, calculando-se quanto o consumo precisaria variar, antes da política analisada ser implementada, para gerar a mesma variação na utilidade média que ocorre após a mudança na política do crédito direcionado.

Note-se que a remoção do programa de crédito direcionado gera uma aumento da TFP, do empreendedorismo, do salário, do produto e do bem-estar. Reduz o tamanho médio das firmas, a desigualdade e gera uma grande inclusão financeira entre as firmas.

Com o fim do crédito direcionado, deixa de haver um subsídio à contratação de crédito, o que diminui a demanda por capital. A taxa de juros da poupança cai para restabelecer o equilíbrio no mercado de crédito, o que leva ao aumento da demanda por capital por parte dos indivíduos antes sem direcionado, tanto pela menor taxa de juros como pela flexibilização da restrição de crédito. O efeito líquido é uma diminuição do capital na economia.

$\overline{2}$ A variação na TFP é calculada por meio do índice de Törnqvist. 
Com o fim do crédito direcionado, os indivíduos pouco produtivos, que só eram empresários por causa do acesso ao crédito direcionado, encerram suas atividades. Além disso, ocorre uma flexibilização da restrição de crédito dos indivíduos anteriormente sem crédito direcionado. Estes dois efeitos geram um aumento da TFP. Porém, a queda do custo de oportunidade do autofinanciamento e da taxa de juros para os indivíduos anteriormente sem direcionado permite que indivíduos menos produtivos se tornem empresários. Este fato, em conjunto com o aumento da rigidez da restrição de crédito dos indivíduos que anteriormente possuíam crédito direcionado, diminui a TFP. No exercício apresentado, os efeitos que elevam a TFP são dominantes e mais do que compensam a queda do capital, gerando um aumento do produto.

Quanto à distribuição de renda, o fim do imposto sobre a renda e o aumento da TFP geram um aumento do salário recebido pelos trabalhadores. Já a dispersão da renda dos empresários diminui, pois agora há uma única taxa de juros que assume um valor intermediário às duas taxas que existiam anteriormente. Além disso,a queda na taxa de juros prejudica mais a renda dos que mais acumulam riqueza, no caso, os indivíduos com maior renda. Portanto, ocorre uma redução do Índice de Gini de renda.

A queda da desigualdade e o aumento do produto acabam por gerar um aumento do bem-estar, o que mostra que o fim dos programas de crédito direcionado gera um ganho de bem-estar para a população.

Por último, vale destacar ainda que a diminuição da taxa de juros para os indivíduos anteriormente sem acesso ao crédito direcionado gera uma considerável inclusão financeira entre as firmas.

\subsubsection{Robustez}

Como não há informações suficientes para calibrar $\phi_{0}$, o modelo será estimado novamente para dois valores alternativos de $\phi_{0}$. Tais valores, serão escolhidos para gerar um intervalo razoável para o tempo médio de permanência no direcionado.

Primeiramente, estima-se o modelo com $\phi_{0}=0.001$, gerando um tempo médio de acesso ao crédito direcionado de 11 anos. A seguir, apresenta-se os valores dos parâmetros estimados e o ajuste do modelo aos dados: 
Tabela 9 - Resultado da calibração

\begin{tabular}{cc}
\hline Parâmetro & Valor \\
\hline \hline Parâmetro da utilidade CRRA $(\gamma)$ & 2.0316 \\
\hline Intensidade dos retornos decrescentes $(\theta)$ & 0.8703 \\
\hline Desconto intertemporal $(\rho)$ & 0.0940 \\
\hline Parâmetro da restrição de crédito $(\eta)$ & 0.0316 \\
\hline Markup do sistema financeiro $(\mu)$ & 6.3406 \\
\hline Parâmetro do processo de difusão da produtividade $(\sigma)$ & 0.0916 \\
\hline Fonte: Produzido pelo autor.
\end{tabular}

Fonte: Produzido pelo autor.

Tabela 10 - Ajuste do modelo aos dados

\begin{tabular}{ccc}
\hline Momento & Dados & Modelo \\
\hline \hline Fração de micro firmas & 0.805 & 0.8032 \\
\hline Fração de firmas pequenas & 0.161 & 0.1527 \\
\hline Fração de firmas médias & 0.017 & 0.0356 \\
\hline Fração de firmas grandes & 0.017 & 0.0085 \\
\hline Fração de firmas que não utilizam o mercado de crédito & 0.492 & 0.4930 \\
\hline Fração de firmas que utilizam apenas o crédito livre & 0.327 & 0.3274 \\
\hline Fração de firmas que utilizam o crédito direcionado & 0.181 & 0.1796 \\
\hline
\end{tabular}

Fonte: Produzido pelo autor.

A próxima tabela apresenta o mesmo exercício contrafactual para os novos parâmetros estimados: 
Tabela 11 - Variação após o fim do programa de direcionamento de crédito

\begin{tabular}{cccc}
\hline Variável & Antes & Depois & Variação percentual \\
\hline \hline Salário recebido pelo trabalhador & 1.0268 & 1.0505 & $2.31 \%$ \\
\hline Taxa de rendimento da poupança & 0.0142 & 0.0092 & $-34.75 \%$ \\
\hline Taxa de juros cobrada dos indivíduos sem acesso ao crédito direcionado & 0.1045 & 0.0675 & $-34.41 \%$ \\
\hline Taxa de juros cobrada dos indivíduos com acesso ao crédito direcionado & 0.0297 & 0.0675 & $127.27 \%$ \\
\hline Restrição de crédito dos indivíduos sem direcionado & 1.3023 & 1.4678 & $12.71 \%$ \\
\hline Restrição de crédito dos indivíduos com direcionado & 2.0628 & 1.4678 & $-28.84 \%$ \\
\hline Produto & 1.8651 & 1.8838 & $1 \%$ \\
\hline Demanda por capital & 6.0167 & 5.9133 & $-1.72 \%$ \\
\hline Fração de empresários na população & 0.0672 & 0.0715 & $6.4 \%$ \\
\hline Fração de firmas que não utilizam o mercado crédito & 0.4930 & 0.4194 & $-17.71 \%$ \\
\hline Fração de micro firmas & 0.8032 & 0.8099 & $1.83 \%$ \\
\hline Fração de firmas pequenas & 0.1505 & 0.1531 & $0.26 \%$ \\
\hline Fração de firmas médias & 0.0356 & 0.0323 & $-9.27 \%$ \\
\hline Gini renda & 0.0085 & 0.0047 & $-44.71 \%$ \\
\hline
\end{tabular}

Fonte: Produzido pelo autor.

Além disto, temos que a TFP aumenta em $1.67 \%$ e o bem-estar em $2.26 \%$.

Em seguida, o modelo é reestimado com $\phi_{0}=0.005$, gerando um tempo médio de acesso ao crédito direcionado de cerca de 2 anos. A seguir apresenta-se o valor dos parâmetros estimados e o ajuste do modelo aos dados:

Tabela 12 - Resultado da calibração

\begin{tabular}{cc}
\hline Parâmetro & Valor \\
\hline \hline Parâmetro da utilidade CRRA $(\gamma)$ & 2.1766 \\
\hline Intensidade dos retornos decrescentes $(\theta)$ & 0.8786 \\
\hline Desconto intertemporal $(\rho)$ & 0.0864 \\
\hline Parâmetro da restrição de crédito $(\eta)$ & 0.0347 \\
\hline Markûmetro do processo de difusão da produtividade $(\kappa)$ & 0.0565 \\
\hline Parâmetro do processo de difusão da produtividade $(\sigma)$ & 0.0977 \\
\hline Fonte: Produzido pelo autor.
\end{tabular}


Tabela 13 - Ajuste do modelo aos dados

\begin{tabular}{ccc}
\hline Momento & Dados & Modelo \\
\hline \hline Fração de micro firmas & 0.805 & 0.8030 \\
\hline Fração de firmas pequenas & 0.161 & 0.1460 \\
\hline Fração de firmas médias & 0.017 & 0.0378 \\
\hline Fração de firmas grandes & 0.017 & 0.0132 \\
\hline Fração de firmas que não utilizam o mercado de crédito & 0.492 & 0.4819 \\
\hline Fração de firmas que utilizam apenas o crédito livre & 0.327 & 0.3382 \\
\hline Fração de firmas que utilizam o crédito direcionado & 0.181 & 0.1799 \\
\hline
\end{tabular}

Fonte: Produzido pelo autor.

A próxima tabela apresenta o mesmo exercício contrafactual realizado na seção anterior para os novos parâmetros estimados:

Tabela 14 - Variação após o fim do programa de direcionamento de crédito

\begin{tabular}{cccc}
\hline Variável & Antes & Depois & Variação percentual \\
\hline \hline Salário recebido pelo trabalhador & 1.0623 & 1.0848 & $2.12 \%$ \\
Taxa de rendimento da poupança & 0.0117 & 0.0073 & $-37.61 \%$ \\
\hline Taxa de juros cobrada dos indivíduos sem acesso ao crédito direcionado & 0.0872 & 0.0545 & $-37.5 \%$ \\
\hline Taxa de juros cobrada dos indivíduos com acesso ao crédito direcionado & 0.0198 & 0.0545 & $177.78 \%$ \\
\hline Restrição de crédito dos indivíduos sem direcionado & 1.3982 & 1.6369 & $17.07 \%$ \\
\hline Restrição de crédito dos indivíduos com direcionado & 2.7575 & 1.6369 & $-40.64 \%$ \\
\hline Produto & 1.9273 & 1.9351 & $0.4 \%$ \\
\hline Demanda por capital & 6.9578 & 6.6922 & $-3.82 \%$ \\
\hline Fração de empresários na população & 0.0636 & 0.0686 & $7.86 \%$ \\
\hline Fração de micro firmas & 0.4819 & 0.3712 & $-27.71 \%$ \\
\hline Fração de firmas pequenas & 0.8030 & 0.8104 & $0.92 \%$ \\
\hline Fração de firmas grandes & 0.1460 & 0.1448 & $-0.82 \%$ \\
\hline Gini renda & 0.0378 & 0.0361 & $-4.5 \%$ \\
\hline
\end{tabular}

Fonte: Produzido pelo autor.

Além disto, temos que a TFP aumenta em $1.61 \%$ e o bem-estar em $2.06 \%$.

Como pode ser observado, os resultados qualitativos se mantêm nas duas novas estimações, mostrando que o resultado encontrado na seção anterior é estável quando 
variamos $\phi_{0}$ dentro de um intervalo razoável.

\subsection{Políticas alternativas}

Como políticas alternativas ao fim do direcionado serão testados dois casos: uma na qual $\phi_{0}$ depende positivamente da produtividade e outra na qual $\phi_{0}$ depende negativamente da riqueza.

Quando $\phi_{0}$ depende positivamente da produtividade, está se assumindo que o banco representativo possui alguma tecnologia que o capacite a identificar os indivíduos mais produtivos. Para testar esta formulação, será usado a seguinte fórmula funcional para $\phi_{0}$ :

$$
\phi_{0}=0.0015 z^{4}
$$

Esta forma funcional é escolhida para gerar uma correlação alta entre o acesso ao crédito direcionado e a produtividade. Note-se que, com esta formulação, um aumento de $50 \%$ no valor da produtividade $z$ implica em um crescimento de cerca de 5 vezes no parâmetro $\phi_{0}$, que indica a frequência do evento "receber direcionamento" para quem não o tem.

Para realizar o exercício contrafactual com essa nova formulação, ajusta-se $\phi_{1}$ de maneira a manter constante a fração de indivíduos com acesso ao crédito direcionado, $\tau$ se ajusta para respeitar a condição de déficit zero do governo, $w$ e $r$ se ajustam para equilibrar os mercados de trabalho e crédito.

A próxima tabela mostra como algumas variáveis de interesse mudam, em comparação com a calibração base, quando adotamos esta nova especificação para $\phi_{0}$ : 
Tabela 15 - Variação após o após a mudança na distribuição do acesso ao crédito direcionado

\begin{tabular}{cccc}
\hline Variável & Antes & Depois & Variação percentual \\
\hline \hline Salário recebido pelo trabalhador & 1.0342 & 1.0424 & $0.79 \%$ \\
\hline Taxa de rendimento da poupança & 0.0137 & 0.0152 & $10.94 \%$ \\
\hline Taxa de juros cobrada dos indivíduos sem acesso ao crédito direcionado & 0.1014 & 0.1122 & $10.65 \%$ \\
\hline Taxa de juros cobrada dos indivíduos com acesso ao crédito direcionado & 0.0279 & 0.0339 & $21.5 \%$ \\
\hline Restrição de crédito dos indivíduos sem direcionado & 1.3079 & 1.2781 & $-2.28 \%$ \\
\hline Restrição de crédito dos indivíduos com direcionado & 2.1193 & 1.9216 & $-9.33 \%$ \\
\hline Produto & 1.8801 & 1.9057 & $1.36 \%$ \\
\hline Demanda por capital & 6.1732 & 6.2808 & $1.74 \%$ \\
\hline Fração de empresários na população & 0.0685 & 0.0656 & $-4.23 \%$ \\
\hline Fração de firmas que não utilizam o mercado crédito & 0.4929 & 0.4701 & $-4.63 \%$ \\
\hline Fração de micro firmas & 0.8069 & 0.7959 & $-1.36 \%$ \\
\hline Fração de firmas pequenas & 0.1505 & 0.1567 & $4.12 \%$ \\
\hline Fração de firmas grandes & 0.0347 & 0.0382 & $10.1 \%$ \\
\hline Gini renda & 0.0079 & 0.0092 & $16.46 \%$ \\
\hline
\end{tabular}

Fonte: Produzido pelo autor.

Além disto, temos que a TFP aumenta em $0.85 \%$ e o bem-estar em $0.79 \%$.

Com esta nova formulção, um maior número de indivíduos com produtividade alta passa a ter acesso ao direcionado, o que eleva a demanda por capital. Para reestabelecer o equilíbrio no mercado de crédito a taxa de juros sobe, o que aumenta a restrição de crédito. Tal movimento diminui a demanda por capital, mas não a ponto de dominar o aumento inicial. 
Figura 8 - Distribuição de produtividade condicional ao acesso ao direcionado

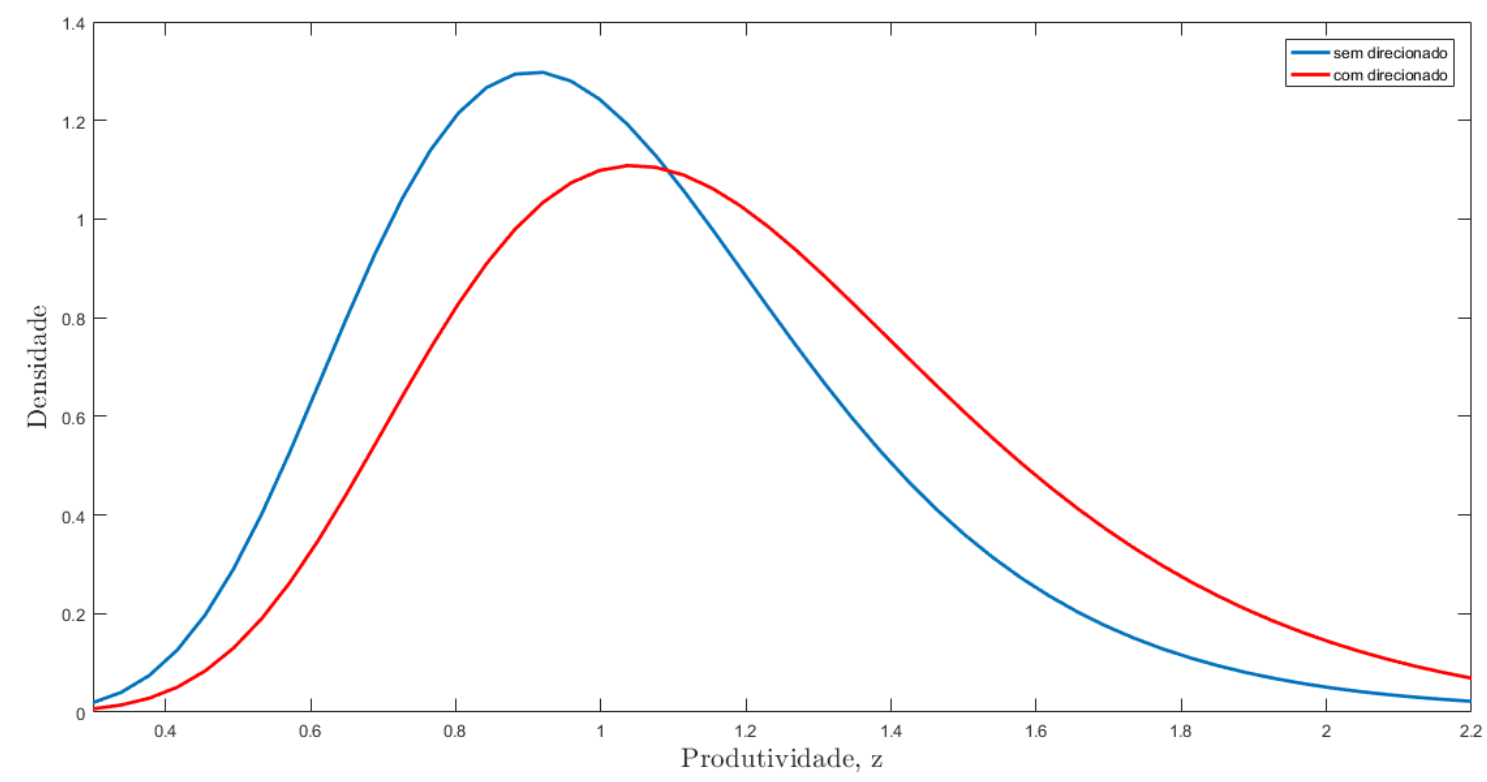

Fonte: Produzido pelo autor.

A focalização do crédito direcionado para os indivíduos mais produtivos e o aumento da taxa de juros acabam por aumentar a produtividade total dos fatores (TFP, ou total factor productivity). Na contramão desse efeito, o aumento da restrição de crédito diminui a TFP. O resultado líquido é um aumento da TFP, o que, em conjunto com uma maior demanda por capital, acabam por elevar o produto. Note-se, no entanto, que o aumento de TFP não é tão elevado quanto a mera remoção do programa

Tal política acaba por concentrar o capital nas firmas mais produtivas e desestimula o empreendedorismo dos indivíduos menos produtivos, o que faz com que a fração de empresários na economia diminua e o tamanho médio das firmas aumente. O salário e o bem-estar aumentam, mas menos do que quando o programa de direcionamento de crédito era extinto. Já a desigualdade de renda aumenta, pois os mais produtivos são naturalmente os que possuem maior renda. Assim, ao focalizar o crédito direcionado para estes a desigualdade se intensifica.

A outra política alternativa de direcionamento que contemplamos é aumentar a probabilidade de direcionamento a indivíduos mais pobres, que são justamente os mais afetados por restrições de crédito. Neste caso, $\phi_{0}$ depende negativamente da riqueza. Para 
testar essa formulação, será usado a seguinte fórmula funcional para $\phi_{0}$ :

$$
\phi_{0}=0.0015 \frac{1}{e^{a}}
$$

O exercício contrafactual é realizado da mesma forma que no exercício anterior. A próxima tabela mostra como algumas variáveis de interesse mudam quando adotamos tal especificação para $\phi_{0}$ :

Tabela 16 - Variação após o após a mudança na distribuição do acesso ao crédito direcionado

\begin{tabular}{cccc}
\hline Variável & Antes & Depois & Variação percentual \\
\hline \hline Salário recebido pelo trabalhador & 1.0342 & 1.0367 & $0.24 \%$ \\
\hline Taxa de rendimento da poupança & 0.0137 & 0.0133 & $-2.9 \%$ \\
\hline Taxa de juros cobrada dos indivíduos sem acesso ao crédito direcionado & 0.1014 & 0.0983 & $-3.06 \%$ \\
\hline Taxa de juros cobrada dos indivíduos com acesso ao crédito direcionado & 0.0279 & 0.0262 & $-6.01 \%$ \\
\hline Restrição de crédito dos indivíduos sem direcionado & 1.3079 & 1.3174 & $0.73 \%$ \\
\hline Restrição de crédito dos indivíduos com direcionado & 2.1193 & 2.1903 & $3.35 \%$ \\
\hline Produto & 1.8801 & 1.8822 & $0.11 \%$ \\
\hline Demanda por capital & 6.1732 & 6.1806 & $0.12 \%$ \\
\hline Fração de empresários na população & 0.0685 & 0.0689 & $0.58 \%$ \\
\hline Fração de firmas que não utilizam o mercado crédito & 0.4929 & 0.4989 & $1.22 \%$ \\
\hline Fração de micro firmas & 0.8069 & 0.8080 & $0.14 \%$ \\
\hline Fração de firmas pequenas & 0.1505 & 0.1507 & $0.13 \%$ \\
\hline Fração de firmas médias & 0.0347 & 0.0338 & $-2.6 \%$ \\
\hline Gini renda & 0.0079 & 0.0075 & $-5.1 \%$ \\
\hline
\end{tabular}

Fonte: Produzido pelo autor.

Além disto, temos que a TFP aumenta em $0.1 \%$ e o bem-estar em $0.24 \%$.

Da equação 3.14, pode-se observar que esta nova formulação para $\phi_{0}$, diminui os incentivos para poupar (e portanto acumular riqueza) dos indivíduos sem acesso ao crédito direcionado. Quanto às decisões de poupança dos indivíduos que acessam o crédito direcionado, o aumento de $V_{0}$ dos indivíduos mais pobres aumenta os incentivos à poupança destes, enquanto a diminuição de $V_{0}$ dos indivíduos mais ricos reduz sua poupança. 
Mesmo com os desincentivos à poupança gerados, o acesso facilitado ao direcionado aos indivíduos mais pobres fornece um mecanismo que facilita a acumulação de riqueza por parte deles. Por outro lado, a demanda por crédito é afetada pelo fato de agora o subsídio estar concentrado em indivíduos mais pobres. O saldo líquido destes efeitos é um excesso de oferta no mercado de crédito que requer uma queda na taxa de juros, o que por sua vez reduz a restrição de crédito.

A queda da taxa de juros, a flexibilização da restrição de crédito e a maior massa de indivíduos pobres entre os que acessam o crédito direcionado, acabam por gerar um aumento do empreendorismo e uma diminuição do tamanho médio das firmas.

Quanto à TFP, a queda na restrição de crédito, gerada pela menor taxa de juros e o fato do crédito direcionado flexibilizar a restrição de crédito dos indivíduos mais restritos tende a aumentá-la. Porém, os desestímulos à poupança, em especial dos mais produtivos tendem a diminuir a TFP. Na prática, estes efeitos praticamente se cancelam. Já o salário aumenta, refletindo o estímulo aos pobres para atividade empreendedora em relação a ofertar trabalho. Aumentam também o bem-estar e o produto, enquanto a desigualdade cai. Porém, a magnitude desses movimentos é menor do que a simples eliminação dos programas de crédito direcionado.

Ambos os exercícios apresentados revelam que correlacionar direcionamento com produtividade e pobreza pode trazer benefícios. Ainda assim os resumtados apontam que a remoção do direcionamento é preferível do ponto de vista da sociedade: há maior aumento do salário, do produto e da TFP, além da maior diminuição da desigualdade de renda. 



\section{Conclusão}

Este trabalho avalia o impacto dos programas de direcionamento de crédito na economia brasileira. Para tanto, foi construído um modelo de equilíbrio geral com agentes heterogêneos em tempo contínuo, que foi calibrado com os dados do SCR e da RAIS para reproduzir a distribuição das formas de financiamento e de tamanho das firmas. A seguir, foram realizados exercícios contrafactuais simulando a remoção do crédito direcionado ou variações na maneira como o crédito direcionado é distribuído. Em especial foram avaliadas a focalização do crédito direcionado para indivíduos mais produtivos ou para os para indivíduos com menor riqueza.

Os resultados obtidos sobre a extinção de direcionamento de crédito corroboram a avaliação dos trabalhos prévios sobre o tema. O fim do crédito direcionado geraria ganhos de produto, diminuição da desigualdade e do tamanho médio das firmas, além de aumentar a produtividade, a inclusão financeira das firmas e o bem-estar. Tais resultados se devem ao fechamento de firmas improdutivas que só existiam devido ao acesso ao crédito direcionado, à diminuição do tamanho de firmas que atuavam em uma escala maior que a ótima, e redução das taxa de juros após o fim dos programas de direcionamento, que torna menos restritas a crédito as firmas não beneficiadas pelo crédito direcionado.

Exercícios contrafatuais apontam que, caso o crédito direcionado fosse focalizado para os indivíduos mais produtivos, haveria um aumento do salário, da produtividade, do produto e do bem-estar em relação à situação atual, mas estes ganhos seriam inferiores aos gerados pela mera eliminação dos programas de direcionamento. Além disso, ocorreria um aumento da desigualdade, já que o benefício do crédito direcionado se concentraria nos indivíduos com maior produtividade, que são naturalmente os mais ricos.

Avaliamos também os impactos de destinar uma maior parte do crédito direcionado a indivíduos com menores níveis de riqueza. Por um lado o crédito direcionado flexibilizaria a restrição de crédito daqueles que são mais afetados por elas, o que contribuiria para gerar eficiencia. Por outro lado, desistimularia a acumulação de capital dos demais indivíduos, em especial dos mais produtivos, o que reduziria a eficiência alocativa. Nossos resultados numéricos indicam ganhos positivos de produtividade, além de melhorias em salários e desigualdade. Porém, tais ganhos seriam menores do que a mera remoção das políticas de direcionamento. 
Este é um trabalho pioneiro no uso do arcabouço de Achdou et al. (2017) para estudar o impacto de políticas praticadas no Brasil sobre o conjunto da economia. Este arcabouço torna computacionalmente tratáveis modelos muito ricos, tanto no volume de predições envolvendo agentes heterogêneos quanto na capacidade de se ajustar a bases de dados detalhadas. Ademais, ele é bastante flexível, permitindo incorporar regras complexas de política, como as adotadas no Brasil. Acreditamos, portanto, que o uso deste arcabouço tem forte potencial de contribuir para o aprendizado sobre a economia brasileira e os impactos de políticas adotadas ou consideradas. 


\section{Referências}

ACHDOU, Y. et al. Income and wealth distribution in macroeconomics: A continuous-time approach. [S.l.], 2017. Citado 6 vezes nas páginas 11, 21, 25, 28, 32 e 52.

AIYAGARI, S. R. Uninsured idiosyncratic risk and aggregate saving. The Quarterly Journal of Economics, MIT Press, v. 109, n. 3, p. 659-684, 1994. Citado 2 vezes nas páginas 24 e 25.

ALFARO, L.; CHARLTON, A.; KANCZUK, F. Plant-size distribution and cross-country income differences. [S.1.], 2008. Citado na página 12.

ANTUNES, A.; CAVALCANTI, T.; VILLAMIL, A. The effects of credit subsidies on development. Economic Theory, Springer, v. 58, n. 1, p. 1-30, 2015. Citado na página 14.

BANERJEE, A. V. A theory of misgovernance. The Quarterly Journal of Economics, MIT Press, v. 112, n. 4, p. 1289-1332, 1997. Citado na página 12.

BANERJEE, A. V. Contracting constraints, credit markets, and economic development abhijit v. banerjee. In: CAMBRIDGE UNIVERSITY PRESS. Advances in Economics and Econometrics: Theory and Applications, Eighth World Congress. [S.l.], 2003. v. 3, p. 1. Citado na página 11.

BANERJEE, A. V.; DUFLO, E. Growth theory through the lens of development economics. Handbook of economic growth, Elsevier, v. 1, p. 473-552, 2005. Citado na página 12.

BANERJEE, A. V.; DUFLO, E. Giving credit where it is due. Journal of Economic Perspectives, v. 24, n. 3, p. 61-80, 2010. Citado 4 vezes nas páginas 11, 12, 21 e 23.

BANERJEE, A. V.; MOLL, B. Why does misallocation persist? American Economic Journal: Macroeconomics, v. 2, n. 1, p. 189-206, 2010. Citado na página 12.

BARLES, G.; SOUGANIDIS, P. E. Convergence of approximation schemes for fully nonlinear second order equations. Asymptotic analysis, IOS Press, v. 4, n. 3, p. 271-283, 1991. Citado na página 28.

BONOMO, M.; BRITO, R. D.; MARTINS, B. The after crisis government-driven credit expansion in brazil: A firm level analysis. Journal of International Money and Finance, Elsevier, v. 55, p. 111-134, 2015. Citado 2 vezes nas páginas 13 e 31.

BUERA, F. J.; KABOSKI, J. P.; SHIN, Y. The macroeconomics of microfinance. [S.l.], 2012. Citado na página 13.

BUERA, F. J.; MOLL, B.; SHIN, Y. Well-intended policies. Review of Economic Dynamics, Elsevier, v. 16, n. 1, p. 216-230, 2013. Citado na página 13.

CANDLER, G. V. et al. Finite-difference methods for continuous-time dynamic programming. QMERBC Codes, Quantitative Macroeconomics \& Real Business Cycles, 1998. Citado na página 28. 
DIXIT, A. K. The art of smooth pasting. [S.1.]: Taylor \& Francis, 1993. v. 55. Citado na página 26.

GOLLIN, D. Getting income shares right. Journal of political Economy, The University of Chicago Press, v. 110, n. 2, p. 458-474, 2002. Citado na página 31.

HSIEH, C.-T.; KLENOW, P. J. Misallocation and manufacturing tfp in china and india. The Quarterly journal of economics, MIT Press, v. 124, n. 4, p. 1403-1448, 2009. Citado na página 12 .

JEONG, H.; TOWNSEND, R. M. Sources of tfp growth: occupational choice and financial deepening. Economic Theory, Springer, v. 32, n. 1, p. 179-221, 2007. Citado na página 13.

KRUSELL, P.; SMITH, A. A. Quantitative macroeconomic models with heterogeneous agents. Econometric Society Monographs, CAMBRIDGE UNIVERSITY PRESS, v. 41, p. 298, 2006. Citado na página 21.

LASRY, J.-M.; LIONS, P.-L. Mean field games. Japanese journal of mathematics, Springer, v. 2, n. 1, p. 229-260, 2007. Citado na página 21.

LAZZARINI, S. G. et al. What do development banks do? evidence from bndes, 2002-2009. 2014. Citado 2 vezes nas páginas 13 e 31.

LJUNGQVIST, L.; SARGENT, T. J. Recursive macroeconomic theory. [S.l.]: MIT press, 2012. Citado na página 21.

LUCAS, R. E. On the size distribution of business firms. The Bell Journal of Economics, JSTOR, p. 508-523, 1978. Citado 3 vezes nas páginas 12, 21 e 22.

MIDRIGAN, V.; XU, D. Y. Finance and misallocation: Evidence from plant-level data. American economic review, v. 104, n. 2, p. 422-58, 2014. Citado na página 13.

MORANDI, L.; REIS, E. et al. Estoque de capital fixo no brasil, 1950-2002. Anais do XXXII Encontro Nacional de Economia, v. 42, 2004. Citado na página 31.

PAULSON, A. L.; TOWNSEND, R. M.; KARAIVANOV, A. Distinguishing limited liability from moral hazard in a model of entrepreneurship. Journal of political Economy, The University of Chicago Press, v. 114, n. 1, p. 100-144, 2006. Citado na página 12.

PAZARBASIOGLU-DUTZ, C. et al. Brazil financial intermediation costs and credit allocation. World Bank, Washington, DC, 2017. Citado 3 vezes nas páginas 15, 20 e 31.

RESTUCCIA, D.; ROGERSON, R. Policy distortions and aggregate productivity with heterogeneous establishments. Review of Economic dynamics, Elsevier, v. 11, n. 4, p. 707-720, 2008. Citado na página 12.

RÍOS-RULL, J.-V. Models with heterogeneous agents. Frontiers of business cycle research, Princeton University Press, p. 98-125, 1995. Citado na página 21.

SOUZA-SOBRINHO, N. F. Macroeconomics of bank interest spreads: Evidence from brazil. Annals of Finance, Springer, v. 6, n. 1, p. 1-32, 2010. Citado na página 14.

STIGLITZ, J. E. The role of the state in financial markets. The World Bank Economic Review, Oxford University Press, v. 7, n. suppl_1, p. 19-52, 1993. Citado na página 12. 
Apêndices 



\section{APÊNDICE A - Derivações Teôricas}

\section{A.1 Derivação do Processo de Difusão da Produtividade}

O logaritmo de $z_{t}$ segue um processo de difusão de Ornstein-Uhlenbeck:

$$
d \log z_{t}=\kappa\left(\log z_{t}\right) d t+\chi d W_{t}
$$

Sendo $W_{t}$ um processo de Wiener. Tal processo de difusão gera uma distribuição estacionária normal para o $\log z_{t}$, com média zero e variância $\frac{\chi^{2}}{2 \kappa}$. Para derivar a expressão para o processo de difusão de $z_{t}$ basta aplicar o Lema de Ito:

$$
d z_{t}=\mu d t+\sigma d W_{t}
$$

Sendo que:

$$
\begin{aligned}
& \mu=\left(-\kappa \log z_{t}+\frac{\chi^{2}}{2}\right) z_{t} \\
& \sigma=\chi^{2} z_{t}^{2}
\end{aligned}
$$

Dessa forma, $z_{t}$ tem distribuição estacionária log-normal com média $\mu_{z}$ e variância $\sigma_{z}^{2}$ dadas respectivamente por:

$$
\begin{aligned}
\mu_{z} & =e^{\frac{\chi^{2}}{4 \kappa}} \\
\sigma_{z}^{2} & =\left(e^{\frac{\chi^{2}}{2 \kappa}}-1\right) e^{\frac{\chi^{2}}{2 \kappa}}
\end{aligned}
$$

\section{A.2 Derivação da Hamilton-Jacobi-Bellman}

A função valor é dada por:

$$
V_{e}\left(a_{t}, z_{t}\right)=\operatorname{Máx}_{c} \int_{t_{0}}^{\infty} \mathrm{e}^{-\rho\left(t-t_{0}\right)} u\left(c_{t}\right) d_{t}
$$

Considere o problema em tempo discreto com períodos de tamanho $\Delta$

$$
V_{e}\left(a_{t}, z_{t}\right)=\operatorname{Máx}_{c} u\left(c_{t}\right) \Delta+e^{-\rho \Delta} \mathbb{E}\left\{V_{e}\left(a_{t+\Delta}, z_{t+\Delta}\right)\right\}
$$

Tome $\Delta \rightarrow 0$ para que seja possível usar a aproximação:

$$
\mathrm{e}^{-\rho \Delta t} \approx 1-\rho \Delta
$$


Dessa forma:

$$
V_{e}\left(a_{t}, z_{t}\right)=\operatorname{Máx}_{c} u\left(c_{t}\right) \Delta+(1-\rho \Delta) \mathbb{E}\left\{V_{e}\left(a_{t+\Delta}, z_{t+\Delta}\right)\right\}
$$

Subtraindo $(1-\rho \Delta) V_{e}\left(a_{t}, z_{t}\right)$ dos dois lados:

$$
\rho \Delta V_{e}\left(a_{t}, z_{t}\right)=\operatorname{Máx}_{c} u\left(c_{t}\right) \Delta+(1-\rho \Delta) \mathbb{E}\left\{V_{e}\left(a_{t+\Delta}, z_{t+\Delta}\right)-V_{e}\left(a_{t}, z_{t}\right)\right\}
$$

Dividindo tudo por $\Delta$ e fazendo $\Delta \rightarrow 0$ :

$$
\rho V_{e}\left(a_{t}, z_{t}\right)=\operatorname{Máx}_{c} u\left(c_{t}\right)+\frac{\mathbb{E}\left\{d V_{e}\left(a_{t}, z_{t}\right)\right\}}{d t}
$$

Utilizando o Lema de Ito:

$$
\begin{aligned}
d V_{e}\left(a_{t}, z_{t}\right)= & \left(\partial_{t} V_{e}\left(a_{t}, z_{t}\right)+\partial_{a} V_{e}\left(a_{t}, z_{t}\right)\left[M_{e}(a, z, w(t), r(t))+r(t) a-c\right]+\partial_{z} V_{e}\left(a_{t}, z_{t}\right) \mu\left(z_{t}\right)\right. \\
& \left.+\frac{\sigma^{2}\left(z_{t}\right)}{2} \partial_{z z} V_{e}\left(a_{t}, z_{t}\right)+\phi_{e}\left[V_{-e}\left(a_{t}, z_{t}\right)-V_{e}\left(a_{t}, z_{t}\right)\right]\right) d t+\partial_{z} V_{e}\left(a_{t}, z_{t}\right) \sigma\left(z_{t}\right) d W_{t}
\end{aligned}
$$

Usando o fato que $\mathbb{E}\left\{d W_{t}\right\}=0$, :

$$
\begin{aligned}
\frac{\mathbb{E}\left\{d V_{e}\left(a_{t}, z_{t}\right)\right\}}{d t}= & \partial_{a} V_{e}\left(a_{t}, z_{t}\right)\left[M_{t}+r a_{t}-c_{t}\right]+\partial_{z} V_{e}\left(a_{t}, z_{t}\right) \mu\left(z_{t}\right)+\frac{\sigma^{2}\left(z_{t}\right)}{2} \partial_{z z} V_{e}\left(a_{t}, z_{t}\right) \\
& +\phi_{e}\left[V_{-e}\left(a_{t}, z_{t}\right)-V_{e}\left(a_{t}, z_{t}\right)\right]+\partial_{t} V_{e}\left(a_{t}, z_{t}\right)
\end{aligned}
$$

Assim:

$$
\begin{aligned}
\rho V_{e}\left(a_{t}, z_{t}\right)= & \operatorname{Máx}_{c} u\left(c_{t}\right)+\partial_{a} V_{e}\left(a_{t}, z_{t}\right)\left[M_{t}+r a_{t}-c_{t}\right]+\partial_{z} V_{e}\left(a_{t}, z_{t}\right) \mu\left(z_{t}\right)+ \\
& \frac{\sigma^{2}\left(z_{t}\right)}{2} \partial_{z z} V_{e}\left(a_{t}, z_{t}\right)+\phi_{e}\left[V_{-e}\left(a_{t}, z_{t}\right)-V_{e}\left(a_{t}, z_{t}\right)\right]+\partial_{t} V_{e}\left(a_{t}, z_{t}\right)
\end{aligned}
$$

\section{A.3 Derivação da Equação de Euler}

A condição de primeira ordem de (3.14) é dada por:

$$
u^{\prime}(c)=\partial_{a} V_{e}(a, z)
$$

Além disso, (3.14) pode ser escrita como:

$$
\rho V_{e}(a, z)=\operatorname{Máx}_{c} u\left(c_{e}(a, z)\right)+\frac{\mathbb{E}_{t}\left\{d V_{e}(a, z)\right\}}{d t}
$$

Aplicando o teorema do envelope:

$$
\rho \partial_{a} V_{e}(a, z)=r u^{\prime}\left(c_{e}(a, z)\right)+\frac{\mathbb{E}_{t}\left\{d \partial_{a} V_{e}(a, z)\right\}}{d t}
$$


Combinando (A.13) e (A.15) e reorganizando os termos, chega-se na equação de Euler do modelo:

$$
u^{\prime}\left(c_{e}(a, z)\right)=[1+(r-\rho) d t] u^{\prime}\left(c_{e}(a, z)\right)+\mathbb{E}_{t}\left\{d u^{\prime}\left(c_{e}(a, z)\right)\right\}
$$





\section{APÊNDICE B - Método Numérico}

Utilizaremos o Método de Diferenças finitas. Para tanto, discretiza-se a riqueza em I intervalos, a produtividade em J intervalos.

A HJB de segunda ordem é uma equação da forma:

$$
F\left(a, z, V_{e}(a, z), D V_{e}(a, z), D^{2} V_{e}(a, z)\right)=0
$$

No nosso caso:

$$
\begin{aligned}
& \rho V_{e}\left(a_{t}, z_{t}\right)-\operatorname{Máx}_{c} u\left(c_{t}\right)+\partial_{a} V_{e}\left(a_{t}, z_{t}\right)\left[M_{t}+r a_{t}-c_{t}\right]+\partial_{z} V_{e}\left(a_{t}, z_{t}\right) \mu\left(z_{t}\right) \\
& +\frac{\sigma^{2}\left(z_{t}\right)}{2} \partial_{z z} V_{e}\left(a_{t}, z_{t}\right)+\phi_{e}\left[V_{-e}\left(a_{t}, z_{t}\right)-V_{e}\left(a_{t}, z_{t}\right)\right]=0
\end{aligned}
$$

O correspondente esquema de diferenças finitas é dado por:

$$
S\left(\Delta a, \Delta z, a, z, V_{e, i, j} ; V_{e, i+1, j}-V_{e, i, j}, V_{e, i, j}-V_{e, i-1, j}, V_{e, i, j+1}-V_{e, i, j}, V_{e, i, j}-V_{e, i, j-1}\right)=0
$$

No caso será usado a seguinte esquema de diferenças finitas:

$$
\begin{aligned}
& \rho \frac{V_{e, i, j}^{n+1}-V_{e, i, j}^{n}}{\Delta}+V_{e, i, j}^{n+1}-u\left(c_{e, i, j}\right)-\partial_{a} V_{e, i, j}^{n+1}\left[M_{e, i, j}^{n}+r a_{i}-c_{e, i, j}^{n}\right] \\
& -\mu_{j} \partial_{z} V_{e, i, j}^{n+1}-\frac{1}{2} \sigma_{j}^{2} \partial_{z z} V_{e, i, j}^{n+1}-\phi_{e}\left(V_{-s, i, j}^{n+1}-V_{e, i, j}^{n+1}\right)=0
\end{aligned}
$$

Onde podemos aproximar as derivadas da equação acima pela aproximações de diferenças Backword ou Forward.

\section{B.1 Condições para convergência}

Barles e Souganidis (1991) estabelecem três condições sobre as quais a solução da equação a diferenças dada por (B.4) converge para a solução de viscosidade da HJB:

- Monotonicidade: O esquema numérico é não crescente em: $V_{e, i+1, j}, V_{e, i+i, j}, V_{e, i, j+1} \mathrm{e}$ $V_{e, i, j-1}$.

- Consistência: Para toda função suave $V$ com derivadas limitadas tem-se que, conforme $\Delta a \rightarrow 0, \Delta z \rightarrow 0, a_{i} \rightarrow a$ e $z_{j} \rightarrow z:$

$$
\begin{gathered}
S\left(\Delta a, \Delta z, a, z, V_{e, i, j} ; V_{e, i+1, j}-V_{e, i, j}, V_{e, i, j}-V_{e, i-1, j}, V_{e, i, j+1}-V_{e, i, j}, V_{e, i, j}-V_{e, i, j-1}\right) \\
\rightarrow F\left(a, z, V_{e}(a, z), D V_{e}(a, z), D^{2} V_{e}(a, z)\right)
\end{gathered}
$$


- Estabilidade: Para todo $\Delta a>0$ e $\Delta z>0, V_{e, i, j}$, tem solução única e independente de $\Delta a>0$ e $\Delta z>0$.

\section{B.2 Upwind Scheme}

Utilizado para satisfazer as condições para convergência. Na dimensão da riqueza, primeiro computa-se a poupança utilizando as aproximações forward e backwards:

$$
\begin{aligned}
& s_{e, i, j, F}=M_{e, i, j}+r a_{i}-\left(u^{\prime}\right)^{-1}\left(\partial_{a} V_{e, i, j, F}\right) \\
& s_{e, i, j, B}=M_{e, i, j}+r a_{i}-\left(u^{\prime}\right)^{-1}\left(\partial_{a} V_{e, i, j, B}\right)
\end{aligned}
$$

Em seguida usa-se a seguinte aproximação:

$$
\partial_{a} V_{e, i, j}=\partial_{a} V_{e, i, j, F} \mathbb{1}_{\left\{s_{e, i, j, F}>0\right\}}+\partial_{a} V_{e, i, j, B} \mathbb{1}_{\left\{s_{e, i, j, B}<0\right\}}+\partial_{a} \bar{V}_{e, i, j} \mathbb{1}_{\left\{s_{e, i, j, F} \leq 0<s_{e, i, j}\right\}}
$$

Como $V$ é côncava em $a$, tem-se que $\partial_{a} V_{e, i, j, F}<\partial_{a} V_{e, i, j, B}$, o que implica em $s_{e, i, j, F}<s_{e, i, j, B}$. Dessa forma, para alguns pontos do grid teremos $s_{e, i, j, F} \leq 0<s_{e, i, j, B}$. Nesses pontos estabelece-se que a poupança é zero, portanto a derivada parcial com relação a $a$ da função valor nesses pontos é dada por $\partial_{a} \bar{V}_{e, i, j}=u^{\prime}\left(M_{e, i, j}+r a_{i}\right)$.

Na dimensão de z não é necessário utilizar tal esquema, pois o processo de difusão de $z_{t}$ é estritamente positivo em todos os pontos e tem condições de fronteira bem definidas. Por esse motivo utiliza-se simplesmente a aproximação forward. ${ }^{1}$

Dessa forma, o nosso esquema numérico é dado por:

$$
\begin{aligned}
\frac{V_{e, i, j}^{n+1}-V_{e, i, j}^{n}}{\Delta}+\rho V_{e, i, j}^{n+1}= & u\left(c_{e, i, j}^{n}\right)+\frac{V_{e, i+1, j}^{n+1}-V_{e, i, j}^{n+1}}{\Delta a}\left[s_{e, i, j}^{n} F\right]^{+}+\frac{V_{e, i, j}^{n+1}-V_{e, i-1, j}^{n+1}}{\Delta a}\left[s_{e, i, j}^{n} B\right]^{-} \\
& +\mu_{j}\left[\frac{V_{e, i, j+1}^{n+1}-V_{e, i, j}^{n+1}}{\Delta z}\right]+\frac{1}{2} \sigma_{j}^{2}\left[\frac{V_{e, i, j+1}^{n+1}-2 V_{e, i, j}^{n+1}+V_{e, i, j-1}^{n+1}}{\Delta z}\right] \\
& +\phi_{e}\left(V_{-s, i, j}^{n+1}-V_{e, i, j}^{n+1}\right)
\end{aligned}
$$

Sendo que:

$$
\begin{aligned}
& {\left[s_{e, i, j, F}^{n}\right]^{+}=\operatorname{Máx}\left\{M_{e, i, j}^{n}+r a_{i}-c_{e, i, j, F}^{n}, 0\right\}} \\
& {\left[s_{e, i, j, B}^{n}\right]^{-}=\operatorname{Min}\left\{M_{e, i, j}^{n}+r a_{i}-c_{e, i, j, B}^{n}, 0\right\}}
\end{aligned}
$$

\footnotetext{
1 Seria possível usar a aproximação backwardsds sem nenhum comprometimento dos resultado.
} 


\section{B.3 Forma Matricial}

Reorganizando os termos:

$$
\begin{aligned}
\frac{V_{e, i, j}^{n+1}-V_{e, i, j}^{n}}{\Delta}+\rho V_{e, i, j}^{n+1}= & u\left(c_{e, i, j}^{n}\right)+V_{e, i-1, j}^{n+1}\left(x_{e, i, j}\right)+V_{e, i, j}^{n+1}\left(y_{e, i, j}+v+\phi_{e}\right)+V_{e, i+1, j}^{n+1}\left(z_{e, i, j}\right) \\
& +V_{e, i, j-1}^{n+1}\left(\chi_{j}\right)+V_{e, i, j+1}^{n+1}\left(\zeta_{j}\right)+V_{-s, i, j}^{n+1}\left(\phi_{e}\right)
\end{aligned}
$$

Onde:

$$
\begin{gathered}
x_{e, i, j}=-\frac{\left[s_{e, i, j, B}^{n}\right]^{-}}{\Delta a} \\
y_{e, i, j}=-\frac{\left[s_{e, i, j, F}^{n}\right]^{+}}{\Delta a}+\frac{\left[s_{e, i, j, B}^{n}\right]^{-}}{\Delta a} \\
z_{e, i, j}=-\frac{\left[s_{e, i, j, F}^{n}\right]^{+}}{\Delta a} \\
\chi_{j}=\frac{\sigma_{j}^{2}}{2(\Delta z)^{2}} \\
v=-\frac{\mu_{j}}{\Delta z}-\frac{\sigma_{j}^{2}}{(\Delta z)^{2}} \\
\zeta=\frac{\mu_{j}}{\Delta z}+\frac{\sigma_{j}^{2}}{2(\Delta z)^{2}}
\end{gathered}
$$

Tal equação acima constitui um sistema de $I \times J \times S$ equações lineares que podem ser escritas em notação matricial.

$$
\frac{1}{\Delta}\left(V^{n+1}-V^{n}\right)+\rho V^{n+1}=u^{n}+A^{n} V^{n+1}
$$

Onde $A^{n}=C^{n}+D+E$, onde as matrizes $(I \mathrm{x} J \mathrm{x} S) \mathrm{x}(I \mathrm{x} J \mathrm{x} S), C^{n}, D, E$, são construídas da seguinte maneira: 


$$
C_{e}^{n}=\left(\begin{array}{ccccccccccccc}
y_{1,1, s} & z_{1,1, s} & 0 & \ldots & \ldots & \ldots & \ldots & \ldots & \ldots & \ldots & \ldots & \ldots & 0 \\
x_{1,2, s} & y_{1,2, s} & z_{1,2, s} & 0 & \ddots & \ddots & \ddots & \ddots & \ddots & \ddots & \ddots & \ddots & \vdots \\
0 & \ddots & \ddots & \ddots & \ddots & \ddots & \ddots & \ddots & \ddots & \ddots & \ddots & \ddots & \vdots \\
\vdots & \ddots & x_{1, I, s} & y_{1, I, s} & 0 & 0 & \ddots & \ddots & \ddots & \ddots & \ddots & \ddots & \vdots \\
\vdots & \ddots & 0 & 0 & y_{2,1, s} & z_{2,1, s} & 0 & \ddots & \ddots & \ddots & \ddots & \ddots & \vdots \\
\vdots & \ddots & \ddots & 0 & x_{2,2, s} & y_{2,2, s} & z_{2,2, s} & 0 & \ddots & \ddots & \ddots & \ddots & \vdots \\
\vdots & \ddots & \ddots & \ddots & \ddots & \ddots & \ddots & \ddots & \ddots & \ddots & \ddots & \ddots & \vdots \\
\vdots & \ddots & \ddots & \ddots & \ddots & 0 & x_{2, I, s} & y_{2, I, s} & 0 & \ddots & \ddots & \ddots & \vdots \\
\vdots & \ddots & \ddots & \ddots & \ddots & \ddots & \ddots & \ddots & \ddots & \ddots & \ddots & \ddots & \vdots \\
\vdots & \ddots & \ddots & \ddots & \ddots & \ddots & \ddots & \ddots & 0 & y_{1, J, s} & z_{1, J, s} & 0 & \vdots \\
\vdots & \ddots & \ddots & \ddots & \ddots & \ddots & \ddots & 0 & x_{2, J, s} & y_{2, J, s} & z_{2, J, s} & 0 & \vdots \\
\vdots & \ddots & \ddots & \ddots & \ddots & \ddots & \ddots & \ddots & \ddots & \ddots & \ddots & \ddots & \vdots \\
0 & \ldots & \ldots & \ldots & \ldots & \ldots & \ldots & \ldots & \ldots & \ldots & \ldots & x_{I, J, s} & y_{I, J, s}
\end{array}\right)
$$

De forma que:

$$
\begin{gathered}
C^{n}=\left(\begin{array}{ccc}
C_{1}^{n} & 0 \\
0 & C_{2}^{n}
\end{array}\right) . \\
\end{gathered}
$$

De forma que:

$$
D=\left(\begin{array}{cc}
D_{1} & 0 \\
0 & D_{2}
\end{array}\right)
$$




$$
\begin{aligned}
& E_{1}=\left(\begin{array}{ccccc}
-\phi_{0} & 0 & \ldots & \ldots & 0 \\
0 & -\phi_{0} & 0 & \ldots & \vdots \\
\vdots & \ddots & \ddots & \ddots & \vdots \\
\vdots & \ddots & \ddots & \ddots & \vdots \\
0 & \ldots & \ldots & \ldots & -\phi_{0}
\end{array}\right) \quad E_{2}=\left(\begin{array}{ccccc}
\phi_{0} & 0 & \ldots & \ldots & 0 \\
0 & \phi_{0} & 0 & \ldots & \vdots \\
\vdots & \ddots & \ddots & \ddots & \vdots \\
\vdots & \ddots & \ddots & \ddots & \vdots \\
0 & \ldots & \ldots & \ldots & \phi_{0}
\end{array}\right) \\
& E_{3}=\left(\begin{array}{ccccc}
\phi_{1} & 0 & \ldots & \ldots & 0 \\
0 & \phi_{1} & 0 & \ldots & \vdots \\
\vdots & \ddots & \ddots & \ddots & \vdots \\
\vdots & \ddots & \ddots & \ddots & \vdots \\
0 & \ldots & \ldots & \ldots & \phi_{1}
\end{array}\right) \quad E_{4}=\left(\begin{array}{ccccc}
-\phi_{1} & 0 & \ldots & \ldots & 0 \\
0 & -\phi_{1} & 0 & \ldots & \vdots \\
\vdots & \ddots & \ddots & \ddots & \vdots \\
\vdots & \ddots & \ddots & \ddots & \vdots \\
0 & \ldots & \ldots & \ldots & -\phi_{1}
\end{array}\right) .
\end{aligned}
$$

De forma que:

$$
E=\left(\begin{array}{ll}
E_{1} & E_{2} \\
E_{3} & E_{4}
\end{array}\right)
$$

Reorganizando os termos em (B.17):

$$
B^{n} V^{n+1}=b^{n} \text {, sendo } B^{n}=\left(\frac{1}{\Delta}+\rho\right) I-A^{n}, b^{n}=u^{n}+\frac{1}{\Delta} V^{n}
$$

\section{B.4 Algoritmo para Estado Estacionário}

O algoritmo para solução consiste em chutar um valor para a função valor $V_{e, i, j}^{0}$. Em especial, escolhe-se o valor da utilidade de não poupar:

$$
V_{e, i, j}^{0}=\frac{M_{e, i, j}+r a_{i}^{0}}{\rho}
$$

Para $n=0,1,2, \ldots$, segue-se as seguintes etapas:

- Calcula-se $\partial_{a} V_{e, i, j}$ por meio de (B.7)

- Calcula-se $c^{n}$ por meio de $c_{e, i, j}^{n}=\left(u^{\prime}\right)^{-1}\left(\partial_{a} v_{e, i, j}^{n}\right)$

- Calcula-se $V^{n+1}$ por meio de (B.18)

- caso $V^{n+1}$ esteja suficientemente próximo de $V^{n}$ pare, caso contrário prosiga novamente do primeiro passo. 